\title{
Use of Western Medicine and Traditional Korean Medicine for Joint Disorders: A Retrospective Comparative Analysis Based on Korean Nationwide Insurance Data
}

\author{
Boyoung Jung, ${ }^{1,2}$ Sukjin Bae, ${ }^{2}$ and Soyoon Kim ${ }^{3,4}$ \\ ${ }^{1}$ Department of Public Health, Graduate School, Yonsei University, 50 Yonsei-ro, Seodaemun-gu, Seoul 03722, Republic of Korea \\ ${ }^{2}$ Research Department, Research Institute of Korean Medicine Policy, 91 Heojun-ro, Gangseo-gu, Seoul 07525, Republic of Korea \\ ${ }^{3}$ Asian Institute for Bioethics and Health Law (WHO Collaborating Centre for Health Law and Bioethics), \\ Yonsei University, 50 Yonsei-ro, Seodaemun-gu, Seoul 03722, Republic of Korea \\ ${ }^{4}$ Department of International Health, Graduate School of Public Health, Yonsei University, 50 Yonsei-ro, \\ Seodaemun-gu, Seoul 03722, Republic of Korea
}

Correspondence should be addressed to Boyoung Jung; happiness630@hanmail.net and Soyoon Kim; syoonkim@yuhs.ac

Received 14 August 2017; Accepted 24 October 2017; Published 6 December 2017

Academic Editor: Gihyun Lee

Copyright (C) 2017 Boyoung Jung et al. This is an open access article distributed under the Creative Commons Attribution License, which permits unrestricted use, distribution, and reproduction in any medium, provided the original work is properly cited.

\begin{abstract}
This study aimed to compare the usage of Western medicine and traditional Korean medicine for treating joint disorders in Korea. Data of claims from all medical institutions with billing statements filed to HIRA from 2011 to 2014 for the four most frequent joint disorders were used for the analysis. Data from a total of 1,100,018 patients who received medical services from 2011 to 2014 were analyzed. Descriptive statistics are presented as type of care and hospital type. All statistical analyses were performed using IBM SPSS for Windows version 21. Of the 1,100,018 patients with joint disorders, 456,642 (41.5\%) were males and 643,376 (58.5\%) were females. Per diem costs of hospitalization in Western medicine clinics and traditional Korean medicine clinics were approximately 160,000 KRW and 50,000 KRW, respectively. Among costs associated with Western medicine, physiotherapy cost had the largest proportion (28.78\%). Among costs associated with traditional Korean medicine, procedural costs and treatment accounted for more than $70 \%$, followed by doctors' fees $(21.54 \%)$. There were distinct differences in patterns of medical care use and cost of joint disorders at the national level in Korea. This study is expected to contribute to management decisions for musculoskeletal disease involving joint disorders.
\end{abstract}

\section{Introduction}

Musculoskeletal diseases are one of the leading causes of disability worldwide. It is a major contributor to health burden and health care costs [1]. Korea has a rapidly aging population due to the decrease in birth rate and increase in life expectancy. The percentage of the population aged 65 years or older will increase from $10.3 \%$ in 2008 to $15.6 \%$ in 2020 and $38.2 \%$ in 2050 [2]. Previous studies have reported findings on the prevalence of musculoskeletal disease $[3,4]$. As the Korean population continues to age, the economic burden of musculoskeletal disease will continue to increase. The total economic burden of treating musculoskeletal is about 8.1 billion dollars [2]. Musculoskeletal diseases are the most common health problems that require the use of traditional
Korean medicine [5], an integral part of prevailing practice and belief systems throughout Korea's history. Starting from the late 19th century, Western medical practices were introduced by Christian missionaries to Korea. These practices quickly supplanted traditional Korean medicine in institutional health care. After the Korean War, the government revived interest in traditional Korean medicine and established colleges that specialize in that field, in addition to colleges of Western medicine [6]. With this historical background, the Korean medical system is characterized by a dual $[7,8]$, mutually exclusive medical system consisting of Western medicine and traditional Korean medicine practices [9]. In Korea, primary care physicians work mostly in solo private practices and are reimbursed on a fee-for-service basis. This 
system enables patients to choose and retain individual physicians regardless of changes in employment status. Therefore, Koreans can use both Western and traditional Korean medicine to treat musculoskeletal disorders. Previous studies have assessed the prevalence and cost of Korean medicine $[5,6,10-13]$. However, most of these studies did not focus on joint disorders [11, 14-16]. Particularly, the statuses of health care utilization associated with joint disorders including the scale of the whole population and health care costs of patients receiving treatment for joint disorders are currently unknown. Therefore, the objective of this study was to analyze claim data submitted to the Korean National Health Insurance (NHI) and assessed by the Health Insurance Review and Assessment Service (HIRA) to compare medical care use between Western medicine and traditional Korean medicine. The results of this study will provide basic information for future management decisions for musculoskeletal diseases especially joint disorders in Korea.

\section{Materials and Methods}

2.1. Data Source. This study used claims data from the 2011-2014 National Patient Sample (NPS) dataset of HIRA. Datasets generated and/or analyzed for this study period are available from the HIRA-NPS repository [17]. The NPS includes 3\% sample data of 2011-2014 national insurance billing data. It can represent the country as a whole (46 million patients). The total number of filed claims and total health expenditure have increased steadily. As of 2011, the total number of filed claims has reached 1.3 billion, with a total health expenditure of $\sim 51.5$ trillion KRW. Patients were stratified according to sex and age in 5-year intervals. These HIRA claim data are compiled by health care providers nationwide. They correspond to the number of claims submitted by patients. Claims from patients with the Medicaid program, government expenditures, and veteran patients are also included in these claim data [18]. All data were deidentified to ensure patient confidentiality. The HIRA Research Ethics Committee of South Korea approved the study protocol.

2.2. Study Population. After reviewing frequent diseases each year in traditional Korean medicine as described previously [19], patients with the following four most frequent joint disorders were included in this study: M17 (gonarthrosis [arthrosis of knee]), M75 (shoulder lesions), S63 (dislocation, sprain, and strain of joints and ligaments at wrist and hand level), and S93 (dislocation, sprain, and strain of joints and ligaments at ankle and foot level). Although dorsalgia (M54) was at the top of the list, it was excluded from analysis since there was no change in ranking by year. To observe changes in the ranking of diseases by year, the remaining joints were included in the study. We focused on musculoskeletal disorders and injuries of the extremities. The diagnoses were coded using the 6th revision of the Korean Classification of Diseases (KCD-6) adapted from the International Classification of Diseases, 10th revision. Data from the billing statements for patients with missing cost data and those with zero total cost were excluded. Patient might have visited more than once during the study period (i.e., more than one claim per patient). Therefore, the number of claims in this study was higher than the total number of patients. A total of 7,996,903 claims for 1,100,018 patients with joint diseases with prefix codes of M17, M75, S63, and S93 in primary diagnoses were included for analysis through discussion of a panel of three clinicians (one public health specialist, one Korean medical doctor, and one statistician). A total of 1,100,018 patients were finally included in our analysis (Figure 1).

2.3. Episode Creating Process. Claims data provided by HIRA included raw data of treatment prescriptions for all patients who received medical services over the course of one year after removing personal and corporate information. Because the claims were submitted monthly, charges in the statement reflected up to one month of information. In other words, patients who had been hospitalized for more than one month would have been charged separately for each month. In such cases, errors such as overestimation of the number of inpatients and underestimation of medical expenses might occur when performing statistical analyses. Therefore, episodes, involving collecting and calibrating several claims charged monthly for one consecutive medical practice were used. In this study, separated claim forms of hospitalized patients were bundled into one hospitalization episode. Variables used in the episode creating process included claims identification key, patient identification key, insurance type, main diagnosis code, treatment type, treatment start date, and treatment end date.

2.4. Main Descriptive Variables. The main descriptive variables were frequency and cost of medical care without addressing a specific hypothesis. Frequency included the number of hospitalizations and outpatient visits in Western medicine and traditional Korean medicine clinics, intervention (surgical and nonsurgical), and annual usage. Rehabilitation-related nonsurgical interventions were classified according to National Evidence-based Healthcare Collaborating Agency reports [20].

Cost included average cost per patient and cost per day (per diem) for joint disorders. Medical costs determined to be eligible for reimbursement by HIRA out of treatment costs were indicated in the submitted insurance claim statement. Medical costs, that is, the sum of benefits reimbursed by the insurer (Korean National Health Insurance Service) to the medical care institutions, were classified as INSUP and self-payment costs paid by the beneficiary (patient) as SLF. It was expressed as total treatment cost in Korean Won $(1,000,000 \mathrm{KRW})$. Each patient's medical costs were calculated as the sum of costs listed on their claims. The average treatment amount was the amount of total medical expenses for one year divided by the number of patients. Per diem was the amount of total medical expenses for one year divided by the number of days of hospitalization or in an outpatient clinic.

The number of reimbursed days included the number of hospitalized days or outpatient visits and in-care drug prescription days. These days were defined based on the number of visits (for outpatient departments) or the length of hospital stay (for inpatient departments) of patients indicated 


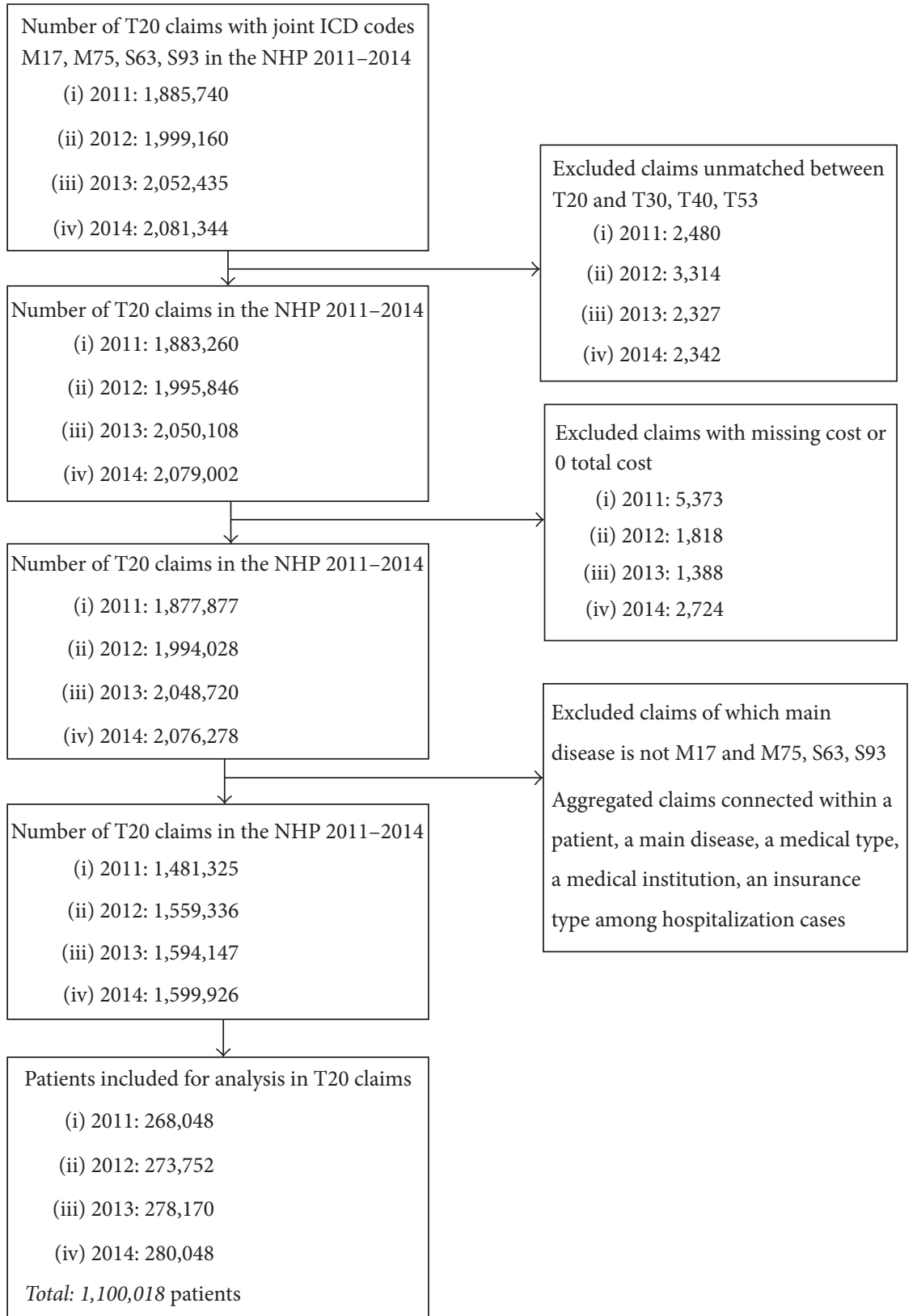

FIGURE 1: Flowchart of the study sample.

in the submitted insurance claim statement [14]. Days per episode were calculated as total reimbursed days divided by the total number of episodes. Patient and medical institutionrelated characteristics are defined as follows.

2.5. Patient Characteristics. Patient characteristics included gender, age, medical insurance type, severity of disease, existence of surgery, and type of medicine. The main attending hospital characteristics included hospital type, region, ownership, the number of beds, the number of Western doctors, and the number of traditional medical practitioners. Patient demographic data obtained from the NHI claims database included gender, age, and medical insurance type
(NHI, Medicaid, and others) at the date of visit of a health care institution and the most frequently visited ones. Individuals were qualified for Medicaid if they had a household income of less than $\$ 600$ per month. Medical services for veterans and beneficiaries were free of charge as government expenditure. Severity was measured using the Charlson Comorbidity Index (CCI) [21] defined as the sum of weights related to each condition for which a patient had available claim data. The CCI score was determined based on the presence of specific ICD-10 codes during one year [22]. In this study, CCI at initiation was used as the CCI score of each patient.

2.6. Medical Institution Characteristics. The types of medical practice were divided into three as follows: traditional, 
Western, and both traditional and Western. Hospital was the main attending medical institution which was visited most frequently by the patient for care. If visit frequency per institution was the same, the main attending hospital was the last health care institution that the patient visited. Medical institutions included Tertiary and General Hospitals, hospitals, long-term care hospitals, Western Clinics, Dental Hospitals and Clinics, Public Health Hospitals (admission facility-equipped health center), Public Health Centers, Local Public Health Clinics, Traditional Hospitals, and Traditional Clinics. Region and ownership were the characteristics of the medical institution that the patient visited.

2.7. Statistical Analysis. Basic characteristics of the study sample are presented as frequencies and percentages. They are presented for each operational definition. Descriptive statistics are presented as type of care and hospital type. All statistical analyses were performed using SPSS version 21 for Windows (IBM Corp., Armonk, NY, USA).

\section{Results}

The general characteristics of the study population are summarized in Table 1.

A total of 1,100,018 patients were included, including 456,642 (41.5\%) males and 643,376 (58.5\%) females. All four years (from 2011 to 2014) showed higher percentages of females than males. Patients under 29 years of age accounted for the largest proportion (23.3\%), followed by patients in their 50 s (20.5\%) and 60s (16.8\%). A total of 1,050,691 (95.5\%) patients were enrolled in the NHI scheme while the remaining 49,012 patients (4.5\%) were enrolled in Medicaid. Patients with knee arthrodesis accounted for the most (24.2\%), followed by those with foot joint disease. More than half (52.5\%) of these patients had knee arthropathy. Approximately 70\% (70.5\%) of patients had mild joint disorder with CCI score of 0 . Among the $1,100,018$ patients, 18,041 (1.6\%) patients underwent surgery while the majority $(98.4 \%)$ of patients underwent nonsurgical procedures. For body regions where basic physical therapy was performed more than three times, the knee and shoulder regions accounted for more than $25 \%$. For regions that needed surgery, the knees accounted for the most. For regions that underwent acupuncture two times or more, the shoulder, hand, and foot areas accounted for $30 \%$ or more (Table 2). Regardless of disease type, only $1.6 \%$ of patients underwent surgery, of which knee surgery was the most frequently performed type (43\% 44\%). The results of nonsurgical intervention distribution are shown in Table 3. The main attending medical institutions included 58,245 (5.3\%) Tertiary and General Hospitals, 118,408 (10.8\%) hospitals, 8,638 (0.8\%) Western Clinics, 592,155 (53.8\%) longterm care hospitals, 6,473 (29.6\%) Traditional Hospitals, and $(28.7 \%)$ Traditional Clinics. However, the results were different for hospitalization and outpatient visits (Table 4). Hospitalization was mainly in the order of hospitals $>$ longterm care hospital $>$ Western Clinic. This is mainly due to the characteristics of patients who require surgery. On the other hand, among the same primary clinic institutions, Traditional
Clinics showed a higher proportion than Western Clinic for outpatients. The admission rates were $96.90 \%$ in Western medicine clinic and $3.10 \%$ in traditional Korean medicine clinics. Among all outpatient visits, $67.85 \%$ involved orthodox medicine while $32.15 \%$ involved traditional Korean medicine. In Western medicine clinics, patients were hospitalized most frequently in hospitals, followed by long-term care hospitals. Hospitalization at hospital level gradually decreased from $37.17 \%$ in 2011 to $36.37 \%$ in 2014 . On the other hand, the percentage of patients who were hospitalized mainly in Traditional Hospitals increased from 2.12\% in 2011 to $3.28 \%$ in 2014. Outpatient visits accounted for most visits to hospitals (Western medicine: 56.26\%; Traditional Korean medicine: $31.69 \%$ ). While the percentage of outpatients at Western medicine clinics steadily increased from $66.19 \%$ in 2011 to $68.93 \%$ by 2014 , the percentage of outpatients at traditional Korean medicine clinics steadily decreased from $33.81 \%$ in 2011 to $31.07 \%$ in 2014 . Most (91.0\%) institutions were privately owned, and most (80.4\%) of them were located outside Seoul. The majority (95.2\%) of institutions had fewer than 5 beds. There was no significant difference among the four groups according to year. The total average treatment cost (RPE) is the sum of INSUP and SLF paid to medical care institution. RPE per patient was $185,933 \mathrm{KRW}$ in $2011,192,290 \mathrm{KRW}$ in 2012, 202,967 KRW in 2013, and 208,739 KRW in 2014. Women incurred more medical expenses in 2011 to 2014 compared to men. Expenditure was increased with age. It peaked in patients in their 70s with a minimum of $377,448 \mathrm{KRW}$ to a maximum of $388,445 \mathrm{KRW}$. In terms of expense by the type of joint lesion, knee lesions (M17) had the highest expense among the four types of joint disorders, followed by shoulder lesions (M75). As the severity of lesion was increased, the expense was also increased. However, the difference in expense was not statistically insignificant. Patients who were hospitalized spent 20 times more than those who were not hospitalized. The average treatment costs per patient in inpatient care and outpatient care were 192,414 and 65,319 KRW, respectively. Patients who used only traditional Korean medicine spent twice less than those who only used Western medicine. The range of RPE for Western medicine was from 181,225 KRW to 198,661 KRW. The range of RPE for traditional Korean medicine was from 82,019 KRW to 96,325 KRW. There were no differences in costs over 400,000 KRW among hospitals that practiced Western medicine (Tertiary and General Hospital, hospital, and Western Clinic). Costs for Western medicine hospitals were the highest, followed by that for Traditional Hospitals and long-term care hospitals (Table 5).

The frequency and total medical expenditures for Western medicine and traditional Korean medicine are shown in Table 6. There were 21,894,252 claims with a cost of $168,024,474$ (1000 KRW) for Western medicine. However, there were only 9,628,946 claims with a cost of $38,602,696$ (1000 KRW) for traditional Korean medicine. The medical expense per visit in an outpatient clinic was 22,000 KRW for Western medicine and about $18,000 \mathrm{KRW}$ for traditional Korean medicine. The day per episode of traditional Korean medicine was longer than that of Western medicine. After analyzing the medical cost of claims for Western medicine 


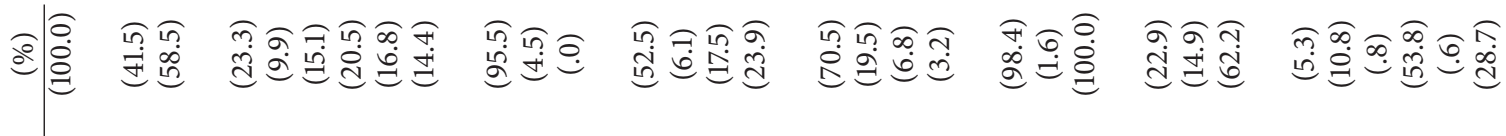

퓽

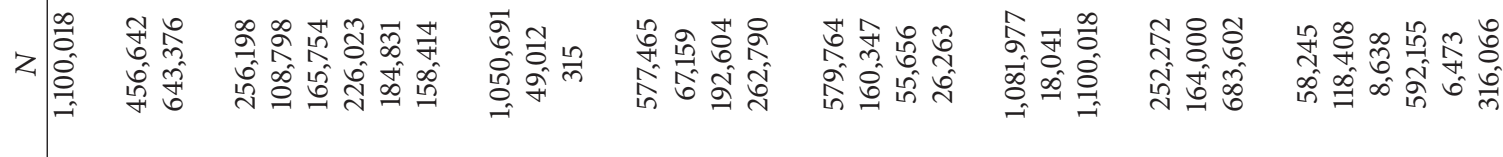

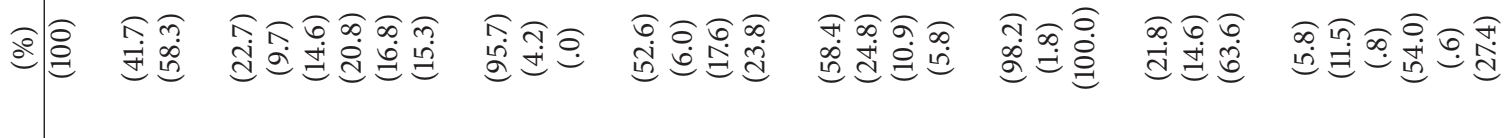

蒙

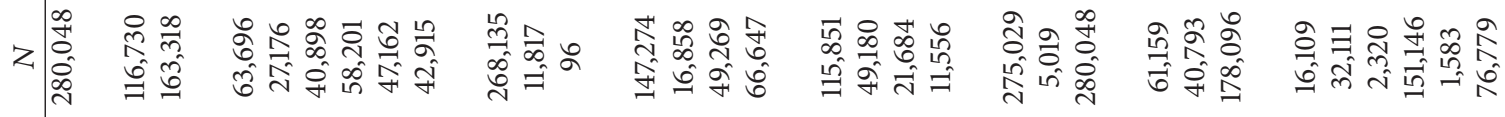

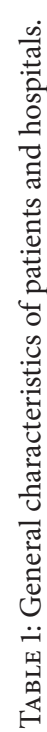

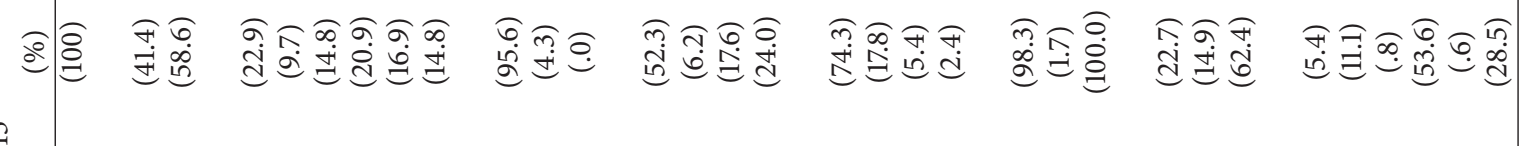

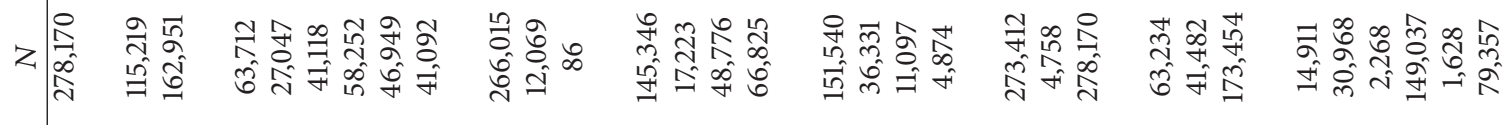

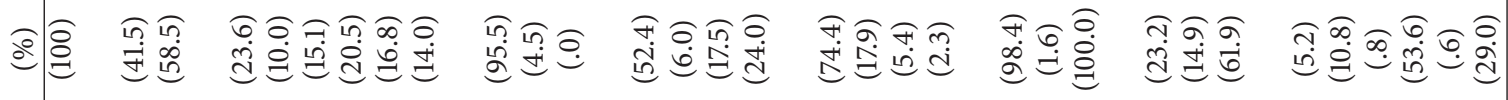
กี้

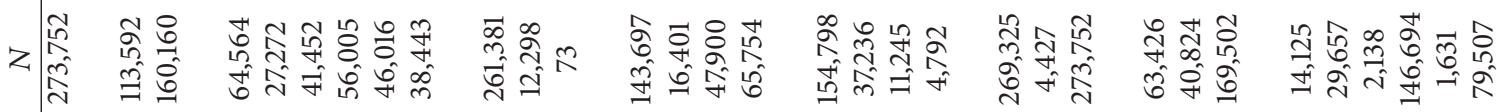
妾

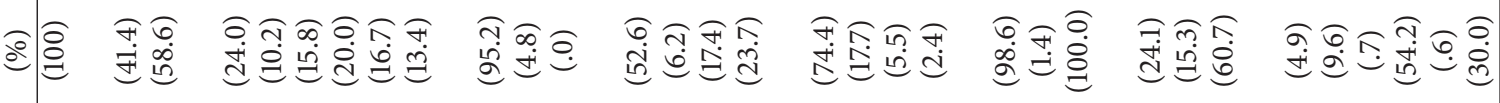
亏ี

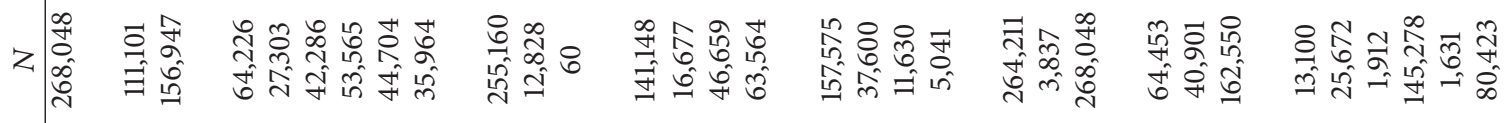

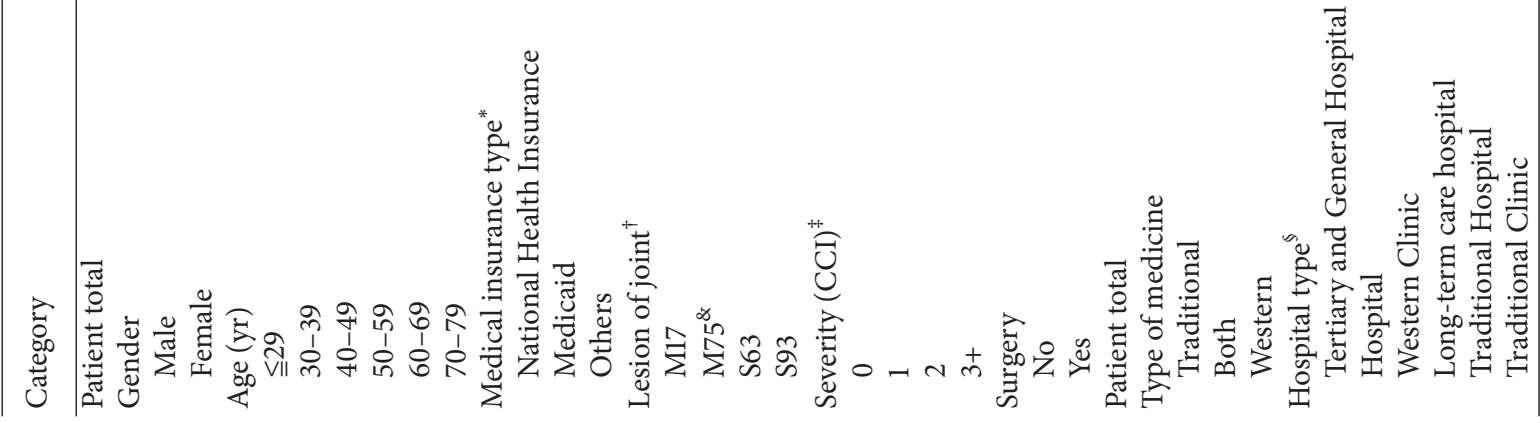




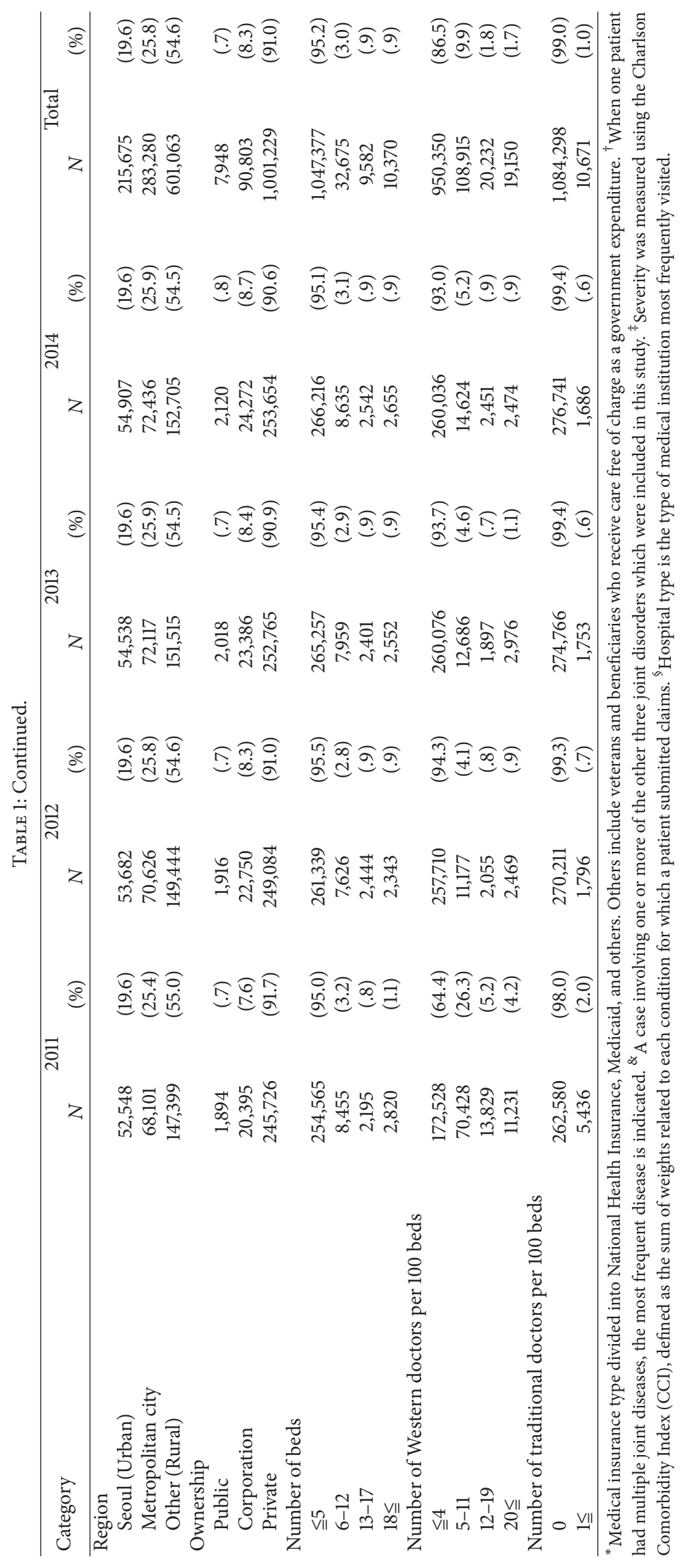




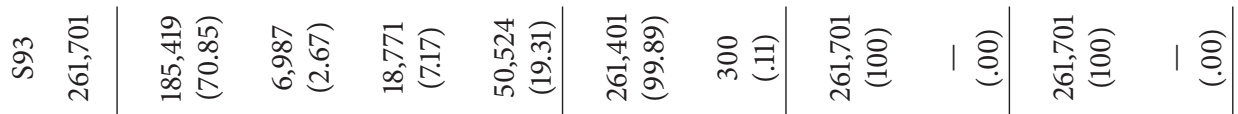

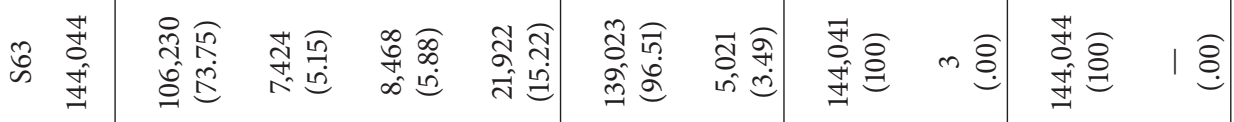

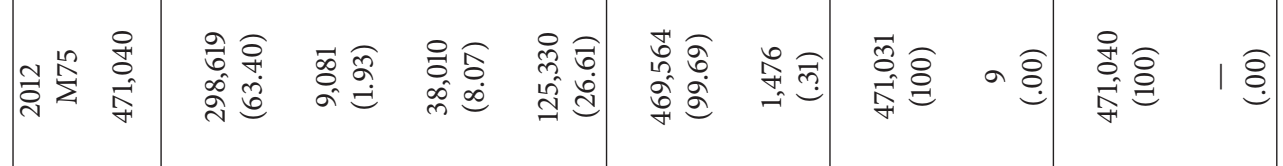

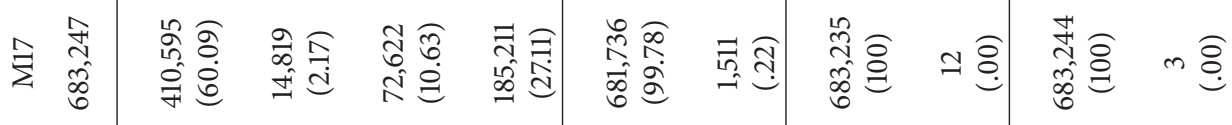

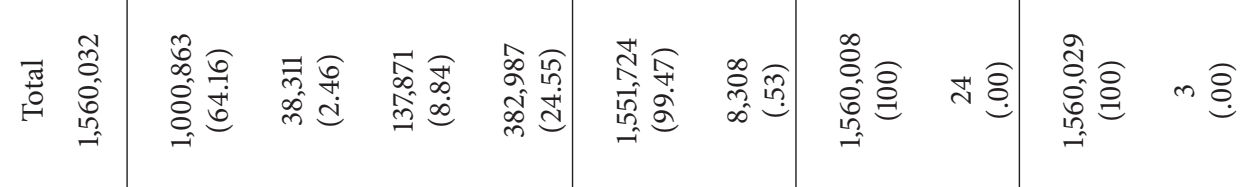

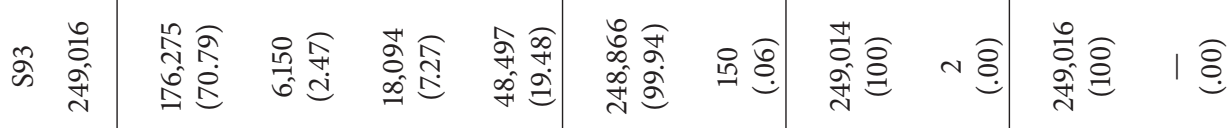

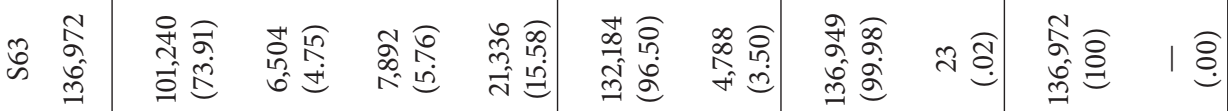

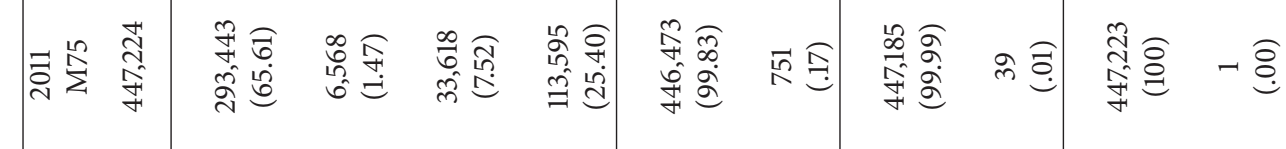

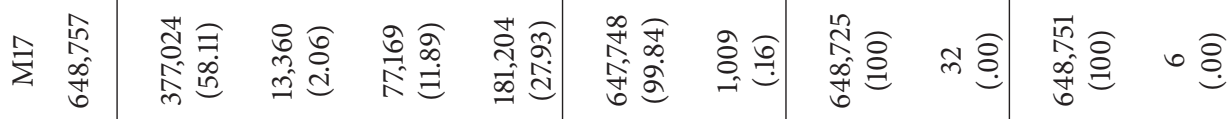

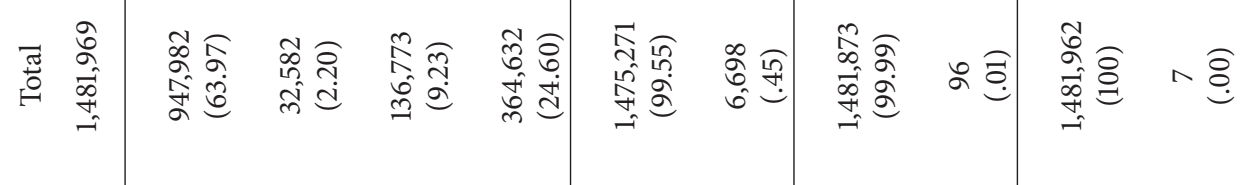

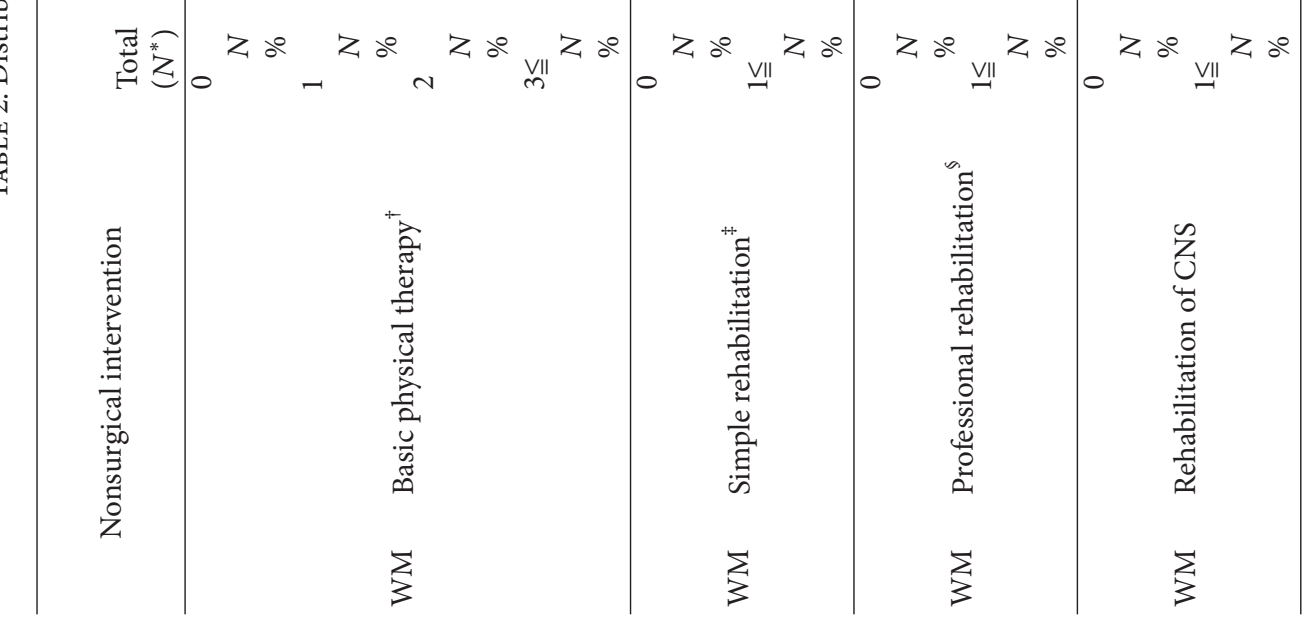




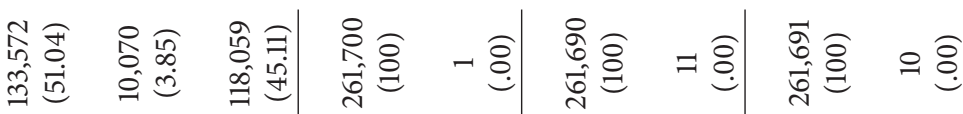

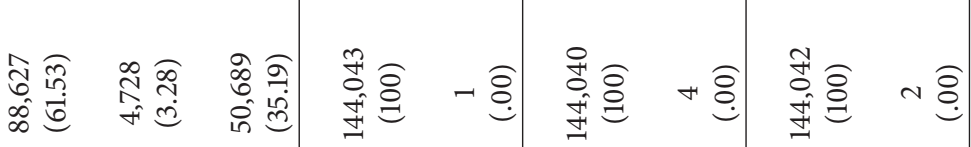

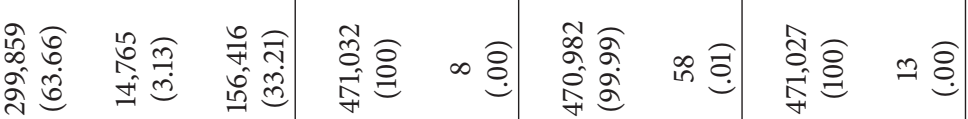

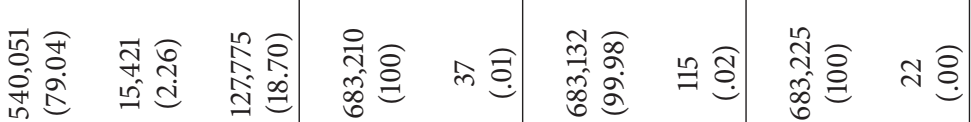

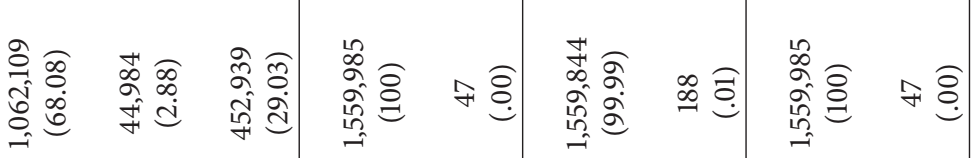

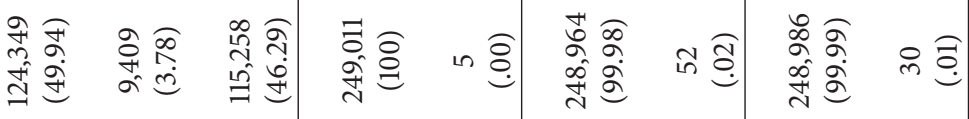

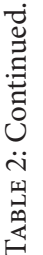

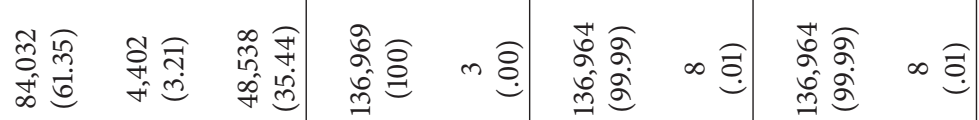

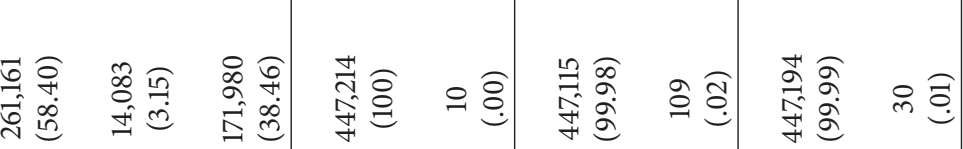

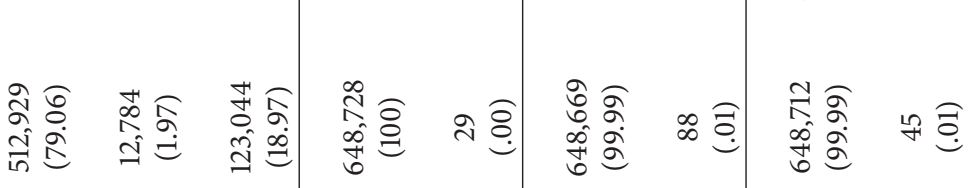

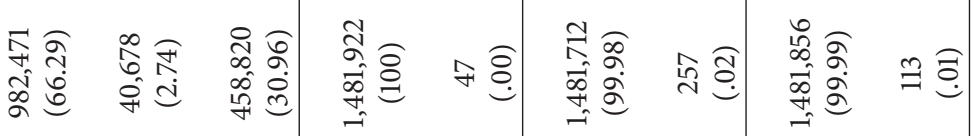

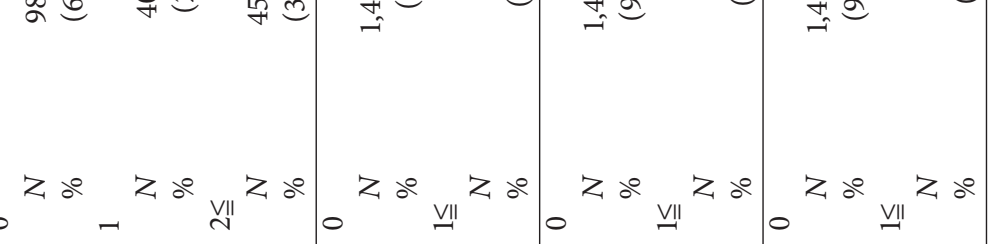

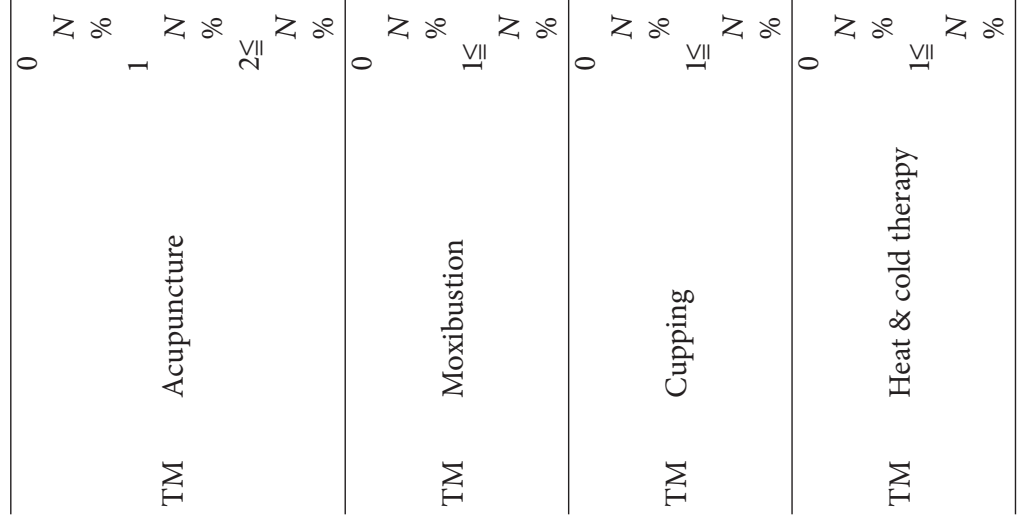




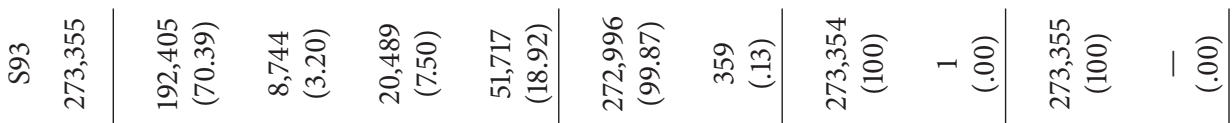

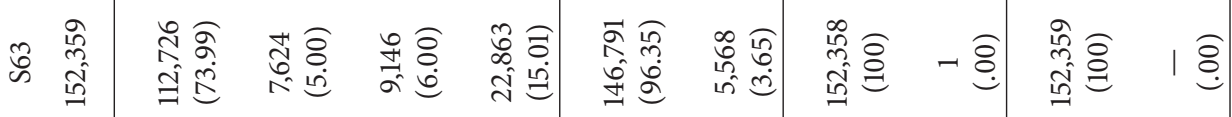

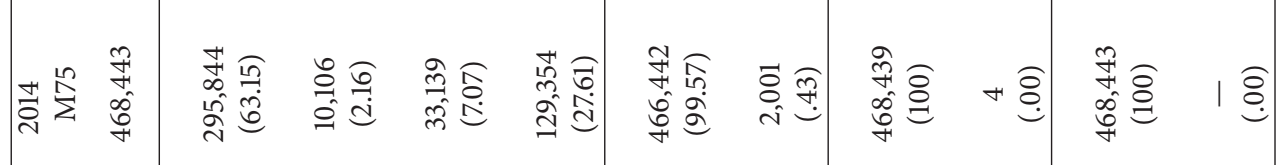

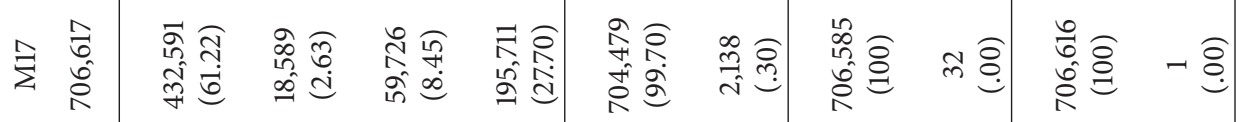

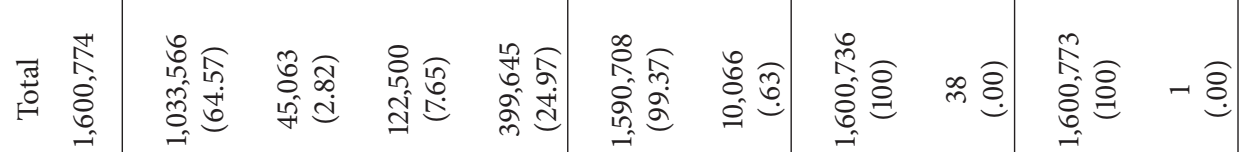

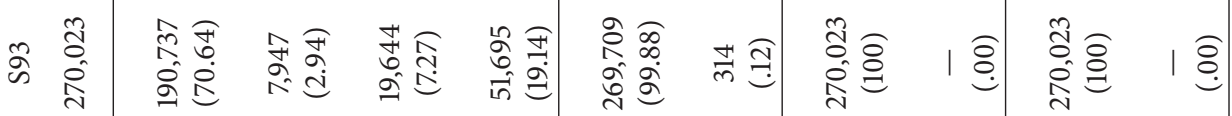

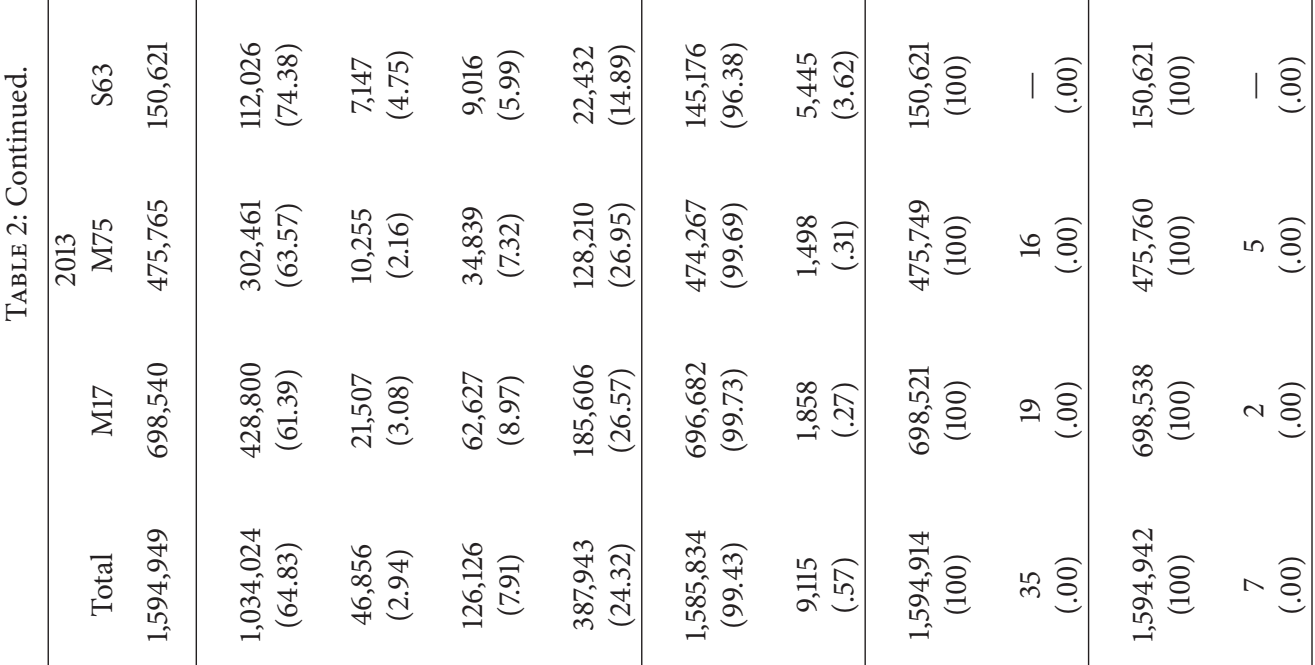

\begin{tabular}{|c|c|c|c|}
\hline 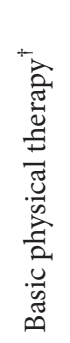 & 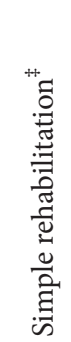 & 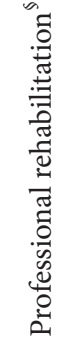 & 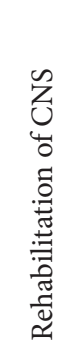 \\
\hline$\sum_{3}$ & $\sum_{3}^{5}$ & $\sum_{3}^{\Sigma}$ & $\sum_{3}$ \\
\hline
\end{tabular}




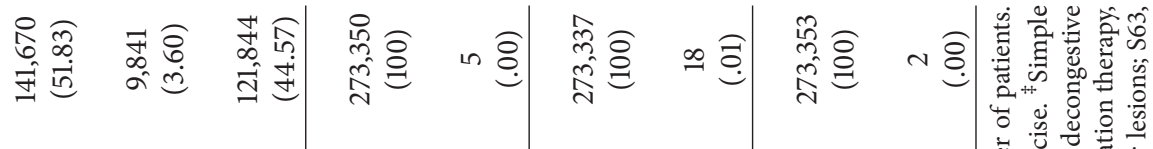

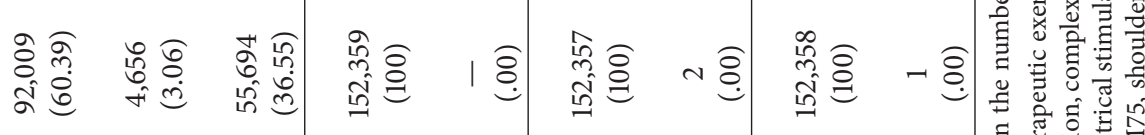

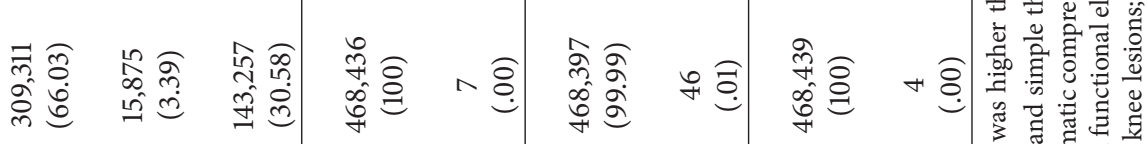

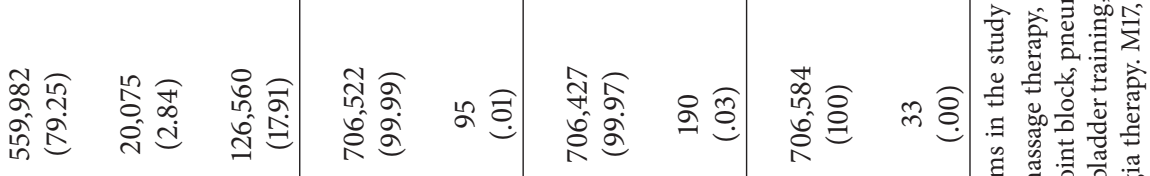

Nล⿵人一

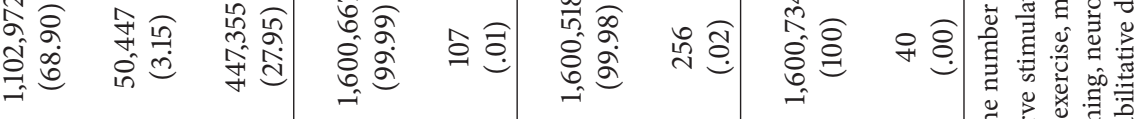

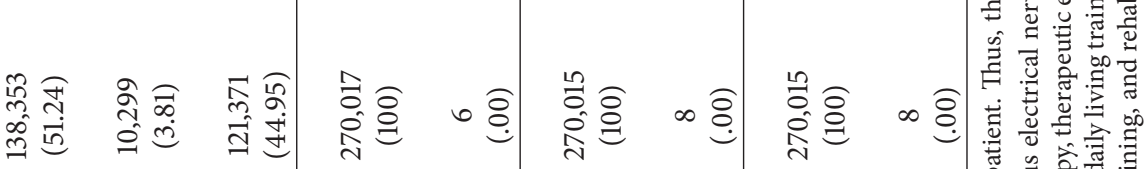

\&

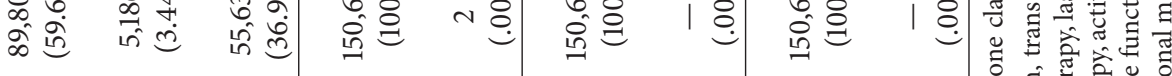

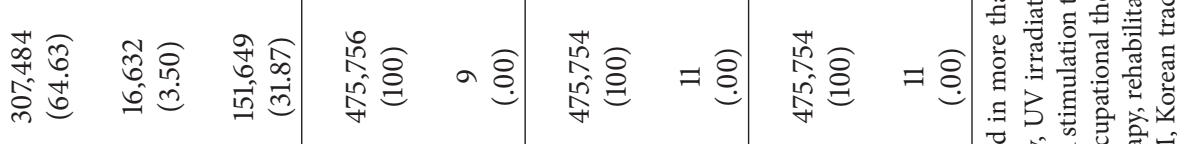

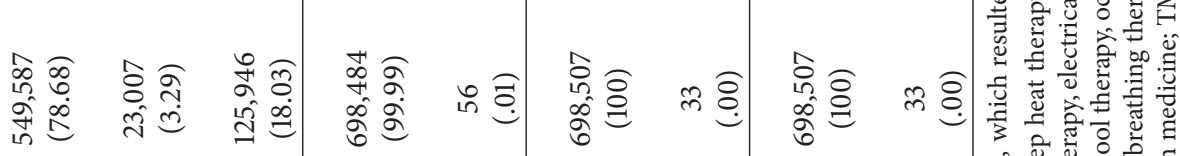

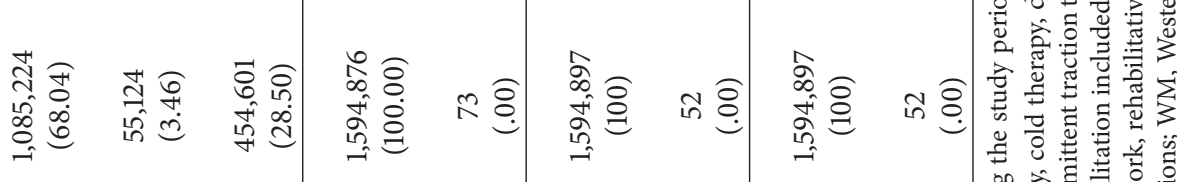

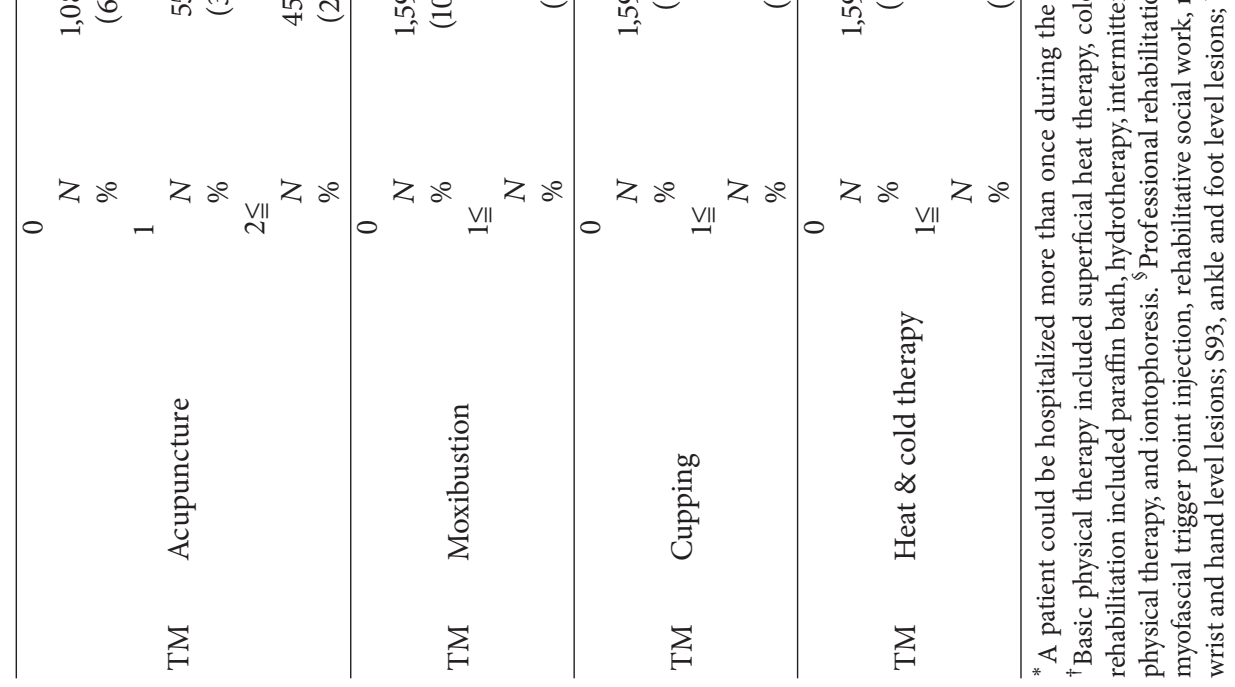


TABLE 3: Comparison of rate of surgery by diagnostic code.

\begin{tabular}{|c|c|c|c|c|c|c|c|c|c|c|c|c|}
\hline \multirow[t]{2}{*}{ Year } & & & \multicolumn{2}{|c|}{ Total } & \multicolumn{2}{|c|}{ Knee lesions [M17] } & \multicolumn{2}{|c|}{$\begin{array}{c}\text { Shoulder lesions } \\
\text { [M75] }\end{array}$} & \multicolumn{2}{|c|}{$\begin{array}{l}\text { Wrist and hand } \\
\text { level [S63] }\end{array}$} & \multicolumn{2}{|c|}{$\begin{array}{c}\text { Ankle and foot } \\
\text { level [S93] }\end{array}$} \\
\hline & & & $N^{*}$ & $\%$ & $N$ & $\%$ & $N$ & $\%$ & $N$ & $\%$ & $N$ & $\%$ \\
\hline & Total & Unit & $1,481,969$ & 100.00 & 648,757 & 43.78 & 447,224 & 30.18 & 136,972 & 9.24 & 249,016 & 16.80 \\
\hline \multirow{5}{*}{2011} & No & $N$ & $1,477,896$ & & 646,826 & & 445,926 & & 136,436 & & 248,708 & \\
\hline & No & $\%$ & (99.73) & & (99.70) & & (99.71) & & (99.61) & & (99.88) & \\
\hline & Yes & $N$ & 4,073 & & 1,931 & & 1,298 & & 536 & & 308 & \\
\hline & & $\%$ & $(.27)$ & & $(.30)$ & & $(.29)$ & & $(.39)$ & & $(.12)$ & \\
\hline & Total & Unit & $1,560,032$ & 100.00 & 683,247 & 43.80 & 471,040 & 30.19 & 144,044 & 9.23 & 261,701 & 16.78 \\
\hline \multirow{5}{*}{2012} & $\mathrm{No}$ & $N$ & $1,555,319$ & & 681,193 & & 469,334 & & 143,450 & & 261,342 & \\
\hline & & $\%$ & $(99.70)$ & & $(99.70)$ & & $(99.64)$ & & (99.59) & & $(99.86)$ & \\
\hline & Yes & $N$ & 4,713 & & 2,054 & & 1,706 & & 594 & & 359 & \\
\hline & & $\%$ & $(.30)$ & & $(.30)$ & & $(.36)$ & & $(.41)$ & & $(.14)$ & \\
\hline & Total & Unit & $1,594,949$ & 100.00 & 698,540 & 43.80 & 475,765 & 29.83 & 150,621 & 9.44 & 270,023 & 16.93 \\
\hline \multirow{5}{*}{2013} & No & $N$ & $1,589,924$ & & 696,372 & & 473,895 & & 150,072 & & 269,585 & \\
\hline & No & $\%$ & (99.68) & & $(99.69)$ & & $(99.61)$ & & $(99.64)$ & & $(99.84)$ & \\
\hline & Yes & $N$ & 5,025 & & 2,168 & & 1,870 & & 549 & & 438 & \\
\hline & & $\%$ & $(.32)$ & & $(.31)$ & & $(.39)$ & & $(.36)$ & & $(.16)$ & \\
\hline & Total & Unit & $1,600,774$ & 100.00 & 706,617 & 44.14 & 468,443 & 29.26 & 152,359 & 9.52 & 273,355 & 17.08 \\
\hline \multirow{4}{*}{2014} & $\mathrm{No}$ & $N$ & $1,595,458$ & & 704,410 & & 466,431 & & 151,772 & & 272,845 & \\
\hline & No & $\%$ & (99.67) & & (99.69) & & (99.57) & & (99.61) & & (99.81) & \\
\hline & Yes & $N$ & 5,316 & & 2,207 & & 2,012 & & 587 & & 510 & \\
\hline & res & $\%$ & $(.33)$ & & $(.31)$ & & $(.43)$ & & $(.39)$ & & (.19) & \\
\hline
\end{tabular}

* A patient could be hospitalized more than once during the study period, which resulted in more than one claim per patient. Thus, the number of claims in the study was higher than the number of patients.

and traditional Korean medicine, the proportion of each item was different. For Western medicine, the proportion of psychiatric costs was the highest $(28.78 \%)$, followed by doctors' fees $(27.7 \%)$, injections (16.59\%), radiotherapy costs (8.74\%), and laboratory costs (7.09\%). For traditional Korean medicine, the proportion of doctors' fees was the highest (26.48\%), followed by procedural costs $(25.16 \%)$, injections $(13.52 \%)$, admission costs $(9.23 \%)$, and psychiatric costs (7.26\%). Regarding traditional Korean medicine, most (70\%) medical treatment costs were procedural costs and treatment costs. Doctors' fees accounted for only $21.54 \%$ of the total cost, similar to doctors' fees for Western medicine. Procedural costs accounted for the most (56.45\%) among total cost for Western medicine. The second largest proportion was doctors' fees (40.49\%). Admission costs, medication costs, and laboratory costs comprised less than $1 \%$ (Table 7 ).

In Table 8, it was not possible to use the inspection and image capturing system of 0 only in the Traditional Clinic because of legal restrictions. According to the region of disease, the knee accounted for the most, followed by the shoulder, foot, and hand in terms of hospitalization and outpatient visits. As the years progressed, the number of inpatient and outpatient visits was also increased for all body regions. Among the hospitalized patients, the number of claims for all years after 2011 increased the most for shoulder joints $(78.43 \%)$ compared to 2011 , followed by knees $(61.93 \%)$, foot $(50.72 \%)$, and hands $(16.29 \%)$. On the other hand, outpatient cases occurred in the following order based on the location of the disease: hand $(11.24 \%)>$ knee $(8.49 \%)>$ ankle $(9.63 \%)>$ shoulder $(4.35 \%)$. According to time (year), difference in current usage patterns was especially different between Western medicine and traditional Korean medicine. Particularly, hospitalization increases for the knee and shoulder areas (shoulder: $105.00 \%$, knee: $250.00 \%$ ) in traditional Korean medicine were higher than those in Western medicine (shoulder: $77.99 \%$, knee: $58.04 \%$ ). The proportion of outpatient visits for the hand region in traditional Korean medicine increased steadily (2012: 4.31\%, 2013: 14.49\%, 2014: $13.46 \%)$. However, the shoulder area showed steady decrease (2011: -8.31\%, 2012: -9.73\%, 2014:-16.45\%) (Table 9).

The costs and length of hospitalization by year are shown in Tables 10-17. Basic physical therapy was the most common nonsurgical intervention in Western medicine while acupuncture was the most common nonsurgical intervention in traditional Korean medicine. Both procedures are steady treatments that require two or more treatments. The proportions of acupuncture and basic physical therapy are almost equal (Table 18).

\section{Discussion}

This study assessed the prevalence and costs of most frequently used treatments for joint disorders in Korea to 


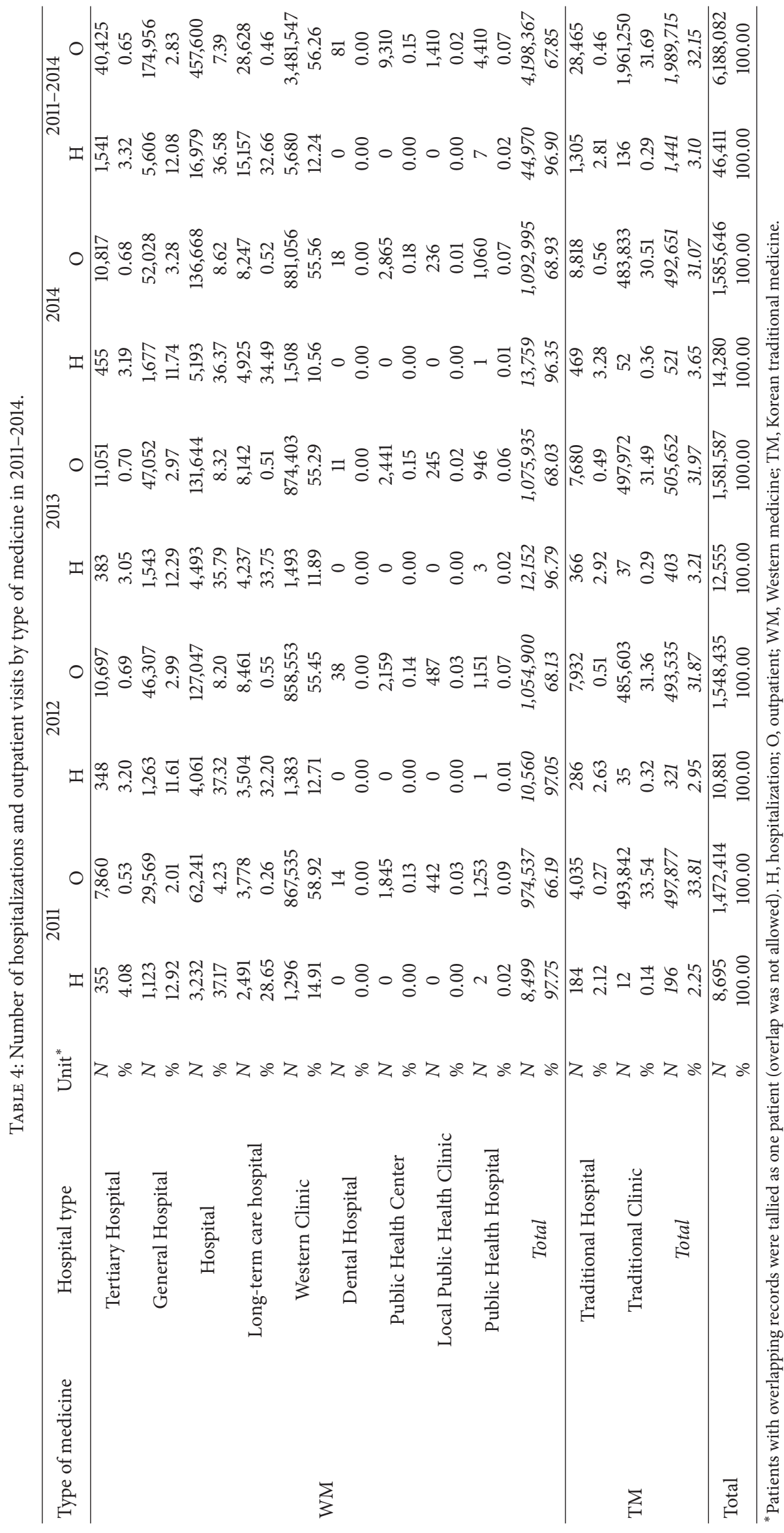




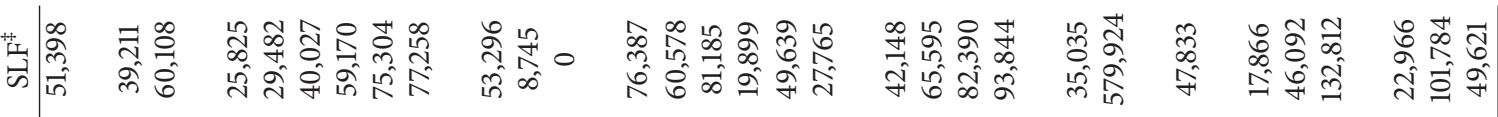

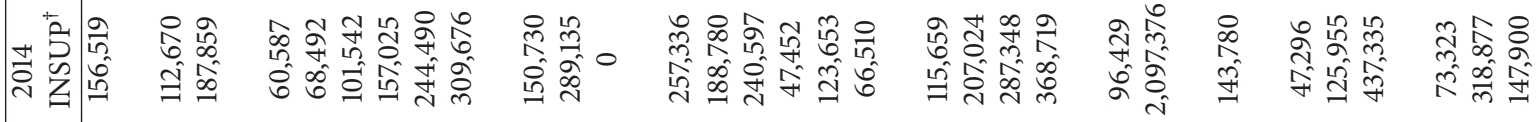

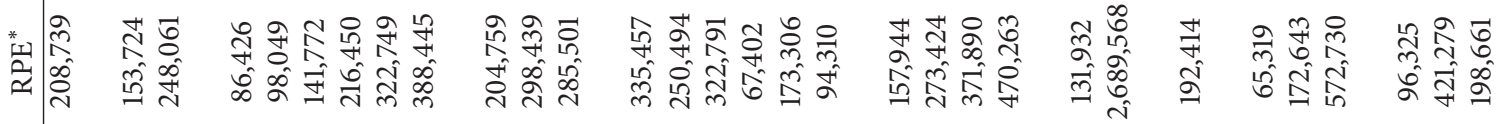

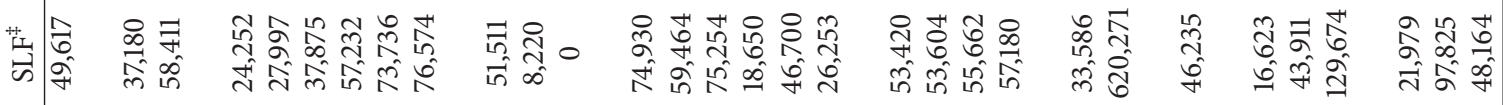

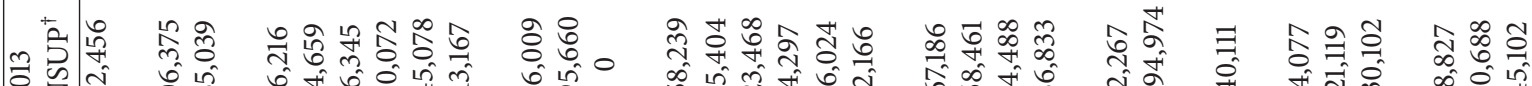

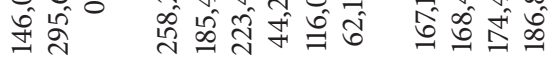

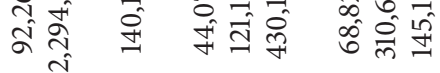

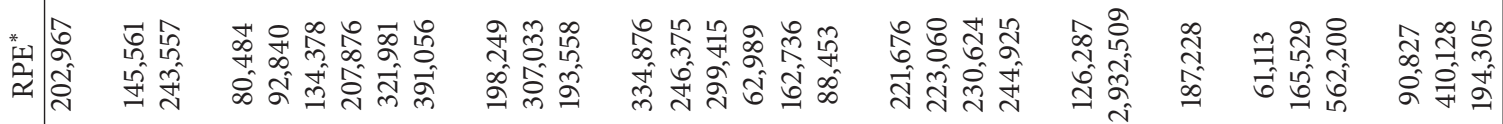

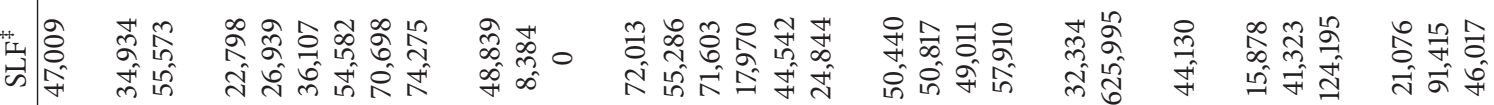

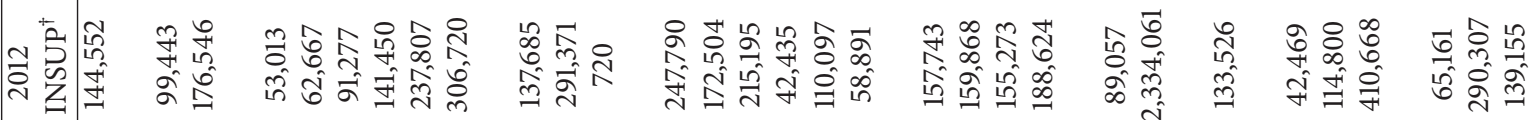

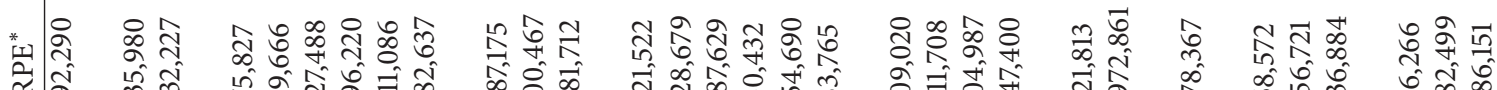

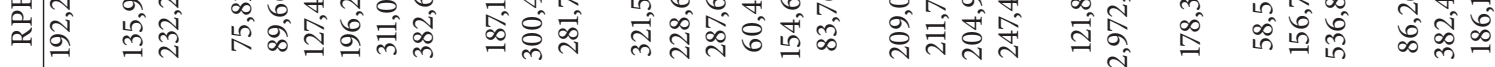

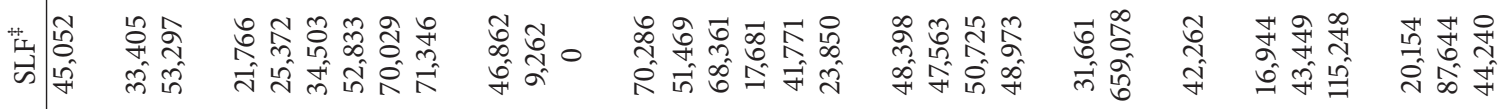

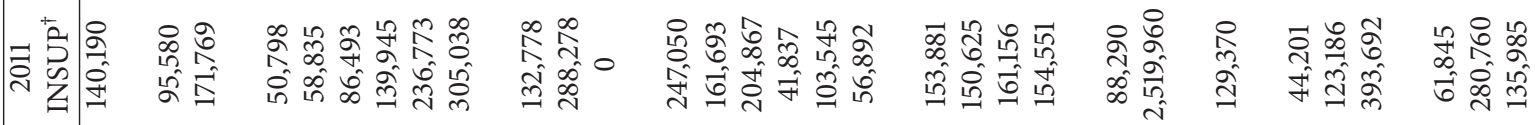

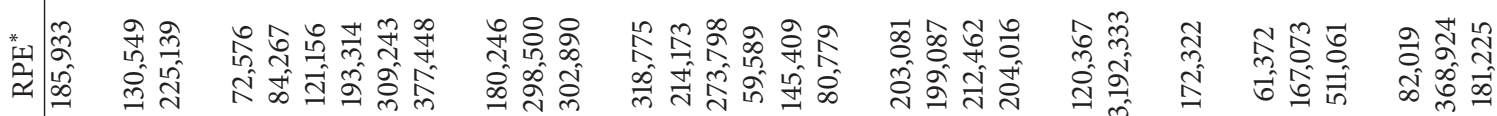

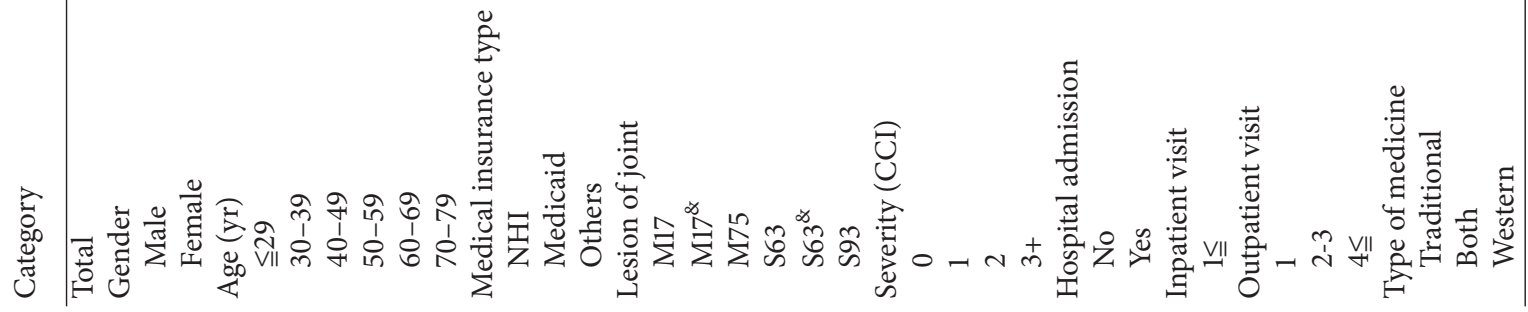




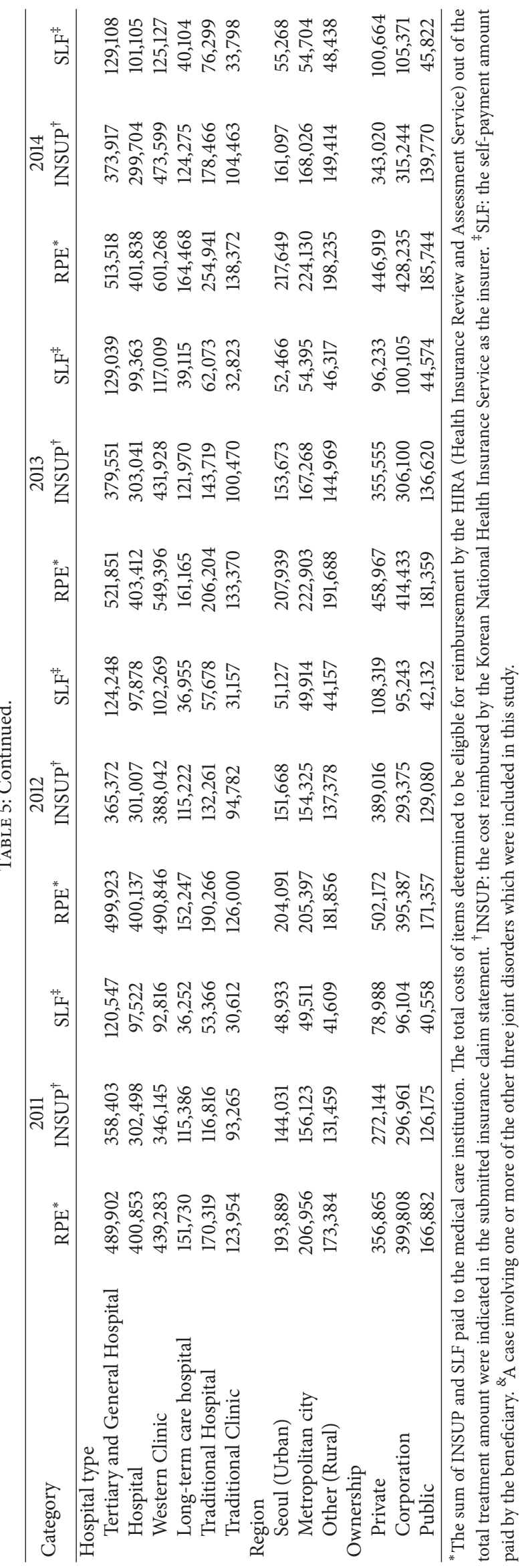


TABLE 6: Comparison of medical costs by type of medicine in 2011-2014.

\begin{tabular}{|c|c|c|c|c|c|c|c|c|}
\hline \multirow{2}{*}{ Unit } & \multirow{2}{*}{ Year } & \multirow{2}{*}{ Type of medicine } & \multicolumn{2}{|c|}{ Frequency } & \multicolumn{3}{|c|}{ Insurance charge } & \multirow{2}{*}{$\begin{array}{c}\text { LOS } \\
\text { Days per episode }\end{array}$} \\
\hline & & & $N^{*}$ & $\%$ & $\operatorname{Cost}^{\dagger}$ & $\%$ & Per diem ${ }^{*}$ & \\
\hline \multirow{12}{*}{$\mathrm{H}$} & \multirow{3}{*}{2011} & WM & 8,499 & 97.75 & 16,542 & 99.37 & 162,276 & 10.98 \\
\hline & & $\mathrm{TM}$ & 196 & 2.25 & 105 & 0.63 & 53,097 & 12.23 \\
\hline & & Total & 8,695 & 100 & 16,647 & 100 & 159,815 & 11.01 \\
\hline & \multirow{3}{*}{2012} & WM & 10,560 & 97.05 & 18,063 & 99.03 & 157,605 & 9.67 \\
\hline & & $\mathrm{TM}$ & 321 & 2.95 & 178 & 0.97 & 57,256 & 12.18 \\
\hline & & Total & 10,881 & 100 & 18,240 & 100 & 154,644 & 9.75 \\
\hline & \multirow{3}{*}{2013} & WM & 12,152 & 96.79 & 19,969 & 98.65 & 155,222 & 9.31 \\
\hline & & $\mathrm{TM}$ & 403 & 3.21 & 216 & 1.35 & 62,217 & 10.78 \\
\hline & & Total & 12,555 & 100 & 20,185 & 100 & 152,237 & 9.35 \\
\hline & \multirow{3}{*}{2014} & WM & 13,759 & 96.35 & 20,077 & 98.65 & 154,829 & 8.51 \\
\hline & & $\mathrm{TM}$ & 521 & 3.65 & 276 & 1.35 & 60,435 & 10.72 \\
\hline & & Total & 14,280 & 100 & 20,353 & 100 & 151,385 & 8.59 \\
\hline \multirow{12}{*}{$\mathrm{O}$} & \multirow{3}{*}{2011} & WM & 974,537 & 66.19 & 23,827 & 71.81 & 22,030 & 1.2 \\
\hline & & $\mathrm{TM}$ & 497,877 & 33.81 & 9,354 & 28.19 & 18,573 & 1.04 \\
\hline & & Total & $1,472,414$ & 100 & 33,181 & 100 & 20,861 & 1.15 \\
\hline & \multirow{3}{*}{2012} & WM & $1,054,900$ & 68.13 & 24,848 & 72.24 & 23,555 & 1.12 \\
\hline & & $\mathrm{TM}$ & 493,535 & 31.87 & 9,551 & 27.76 & 19,352 & 1.03 \\
\hline & & Total & $1,548,435$ & 100 & 34,399 & 100 & 22,215 & 1.09 \\
\hline & \multirow{3}{*}{2013} & WM & $1,075,935$ & 68.03 & 26,203 & 72.24 & 24,354 & 1.11 \\
\hline & & $\mathrm{TM}$ & 505,652 & 31.97 & 10,071 & 27.76 & 19,917 & 1.03 \\
\hline & & Total & $1,581,587$ & 100 & 36,274 & 100 & 22,935 & 1.08 \\
\hline & \multirow{3}{*}{2014} & WM & $1,092,995$ & 68.93 & 27,887 & 73.19 & 25,514 & 1.1 \\
\hline & & $\mathrm{TM}$ & 492,651 & 31.07 & 10,218 & 26.81 & 20,740 & 1.03 \\
\hline & & Total & $1,585,646$ & 100 & 38,104 & 100 & 24,031 & 1.08 \\
\hline
\end{tabular}

* A patient could be hospitalized more than once during the study period, which resulted in more than one claim per patient. Thus, the number of claims in the study was higher than the number of patients. ${ }^{\dagger}$ Costs determined to be eligible for reimbursement by the HIRA (Health Insurance Review and Assessment Service) out of the total treatment amount were indicated in the submitted insurance claim statement. Costs are expressed in Korean Won (1,000,000 KRW). ${ }^{\ddagger}$ Per diem is the average daily cost of services covered by National Health Insurance. It is expressed in Korean Won. ${ }^{\S}$ Days per episode are the total number of reimbursed days divided by the total number of episodes. The number of reimbursed days includes the number of hospitalized days or outpatient visits and in-care drug prescription days. $\mathrm{H}$, hospitalization; O, outpatient; WM, Western medicine; TM, Korean traditional medicine.

provide basic information for future usual care guidelines that may reduce health expenditures and help solve National Health Insurance deficits. This study used the 2011-2014 HIRA-NPS data consisting of 3\% age-stratified and genderstratified random samples. It appropriately reflected the South Korean population of 2011-2014 to capture real-world medical use and cost in joint disorders.

The results of the study showed that the proportion of female patients was higher compared to that of male patients. This is consistent with previous findings showing that women are more likely to utilize health care than men $[23,24]$. This might be due to gender role differences such as occupation, hours of work, and occupational activities including housework and biological factors. Women are typically responsible for childcare and housework while men are typically expected to have a job [25].

The shoulder and knee joints accounted for the most hospital visits and increased steeply. In Korea, musculoskeletal disease accounted for $28.2 \%$ of National Health Insurance Corporation (NHIC) inpatient and outpatient claims. Knee joint disease has been ranked the 6th among reasons for inpatient care visit and the 5 th among reasons for outpatient care visit among the population aged 65 years or older [26]. The incidence of gonarthrosis has been steadily increasing in Korea. Its rate in women was much higher than that in men [27].

While Western Clinics were the most frequently visited medical institution type between 2011 and 2014, the finding that Traditional Clinics were the next most frequently visited in this study was noteworthy. The Korean medical system is characterized by both Western and traditional Korean medical practices. In 2014, the number of claims from Western medicine was 49,031 for Tertiary and General Hospitals and 16,935 for hospitals and clinics. On the contrary, the number of claims from traditional Korean medicine was 14,729 for hospitals and 7,690 for clinics [26]. These circumstances reflect the high proportion of traditional Korean medicine use for joint disorders [9]. Our results are consistent with previous results showing that Traditional Clinics are the second most visited institution by patients with nonspecific low back pain [14]. 


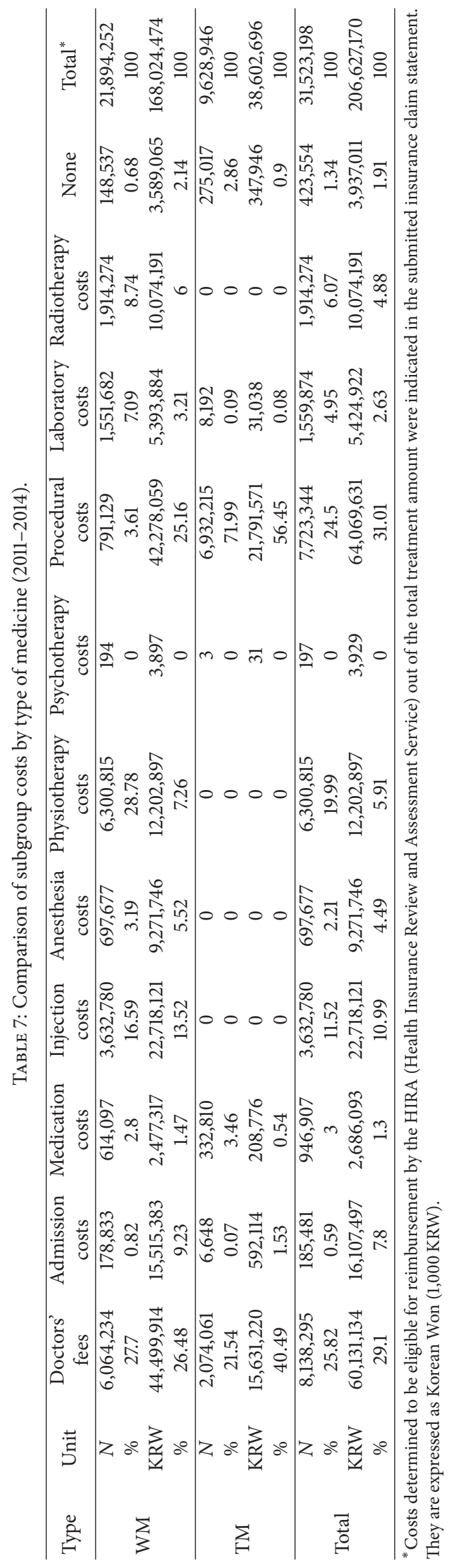




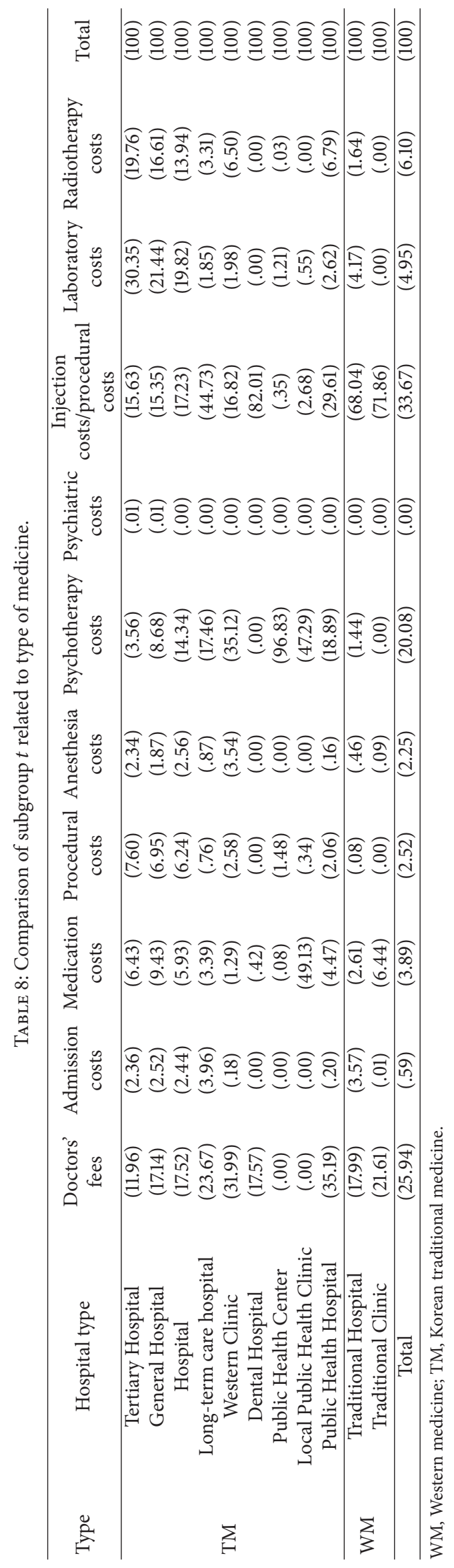




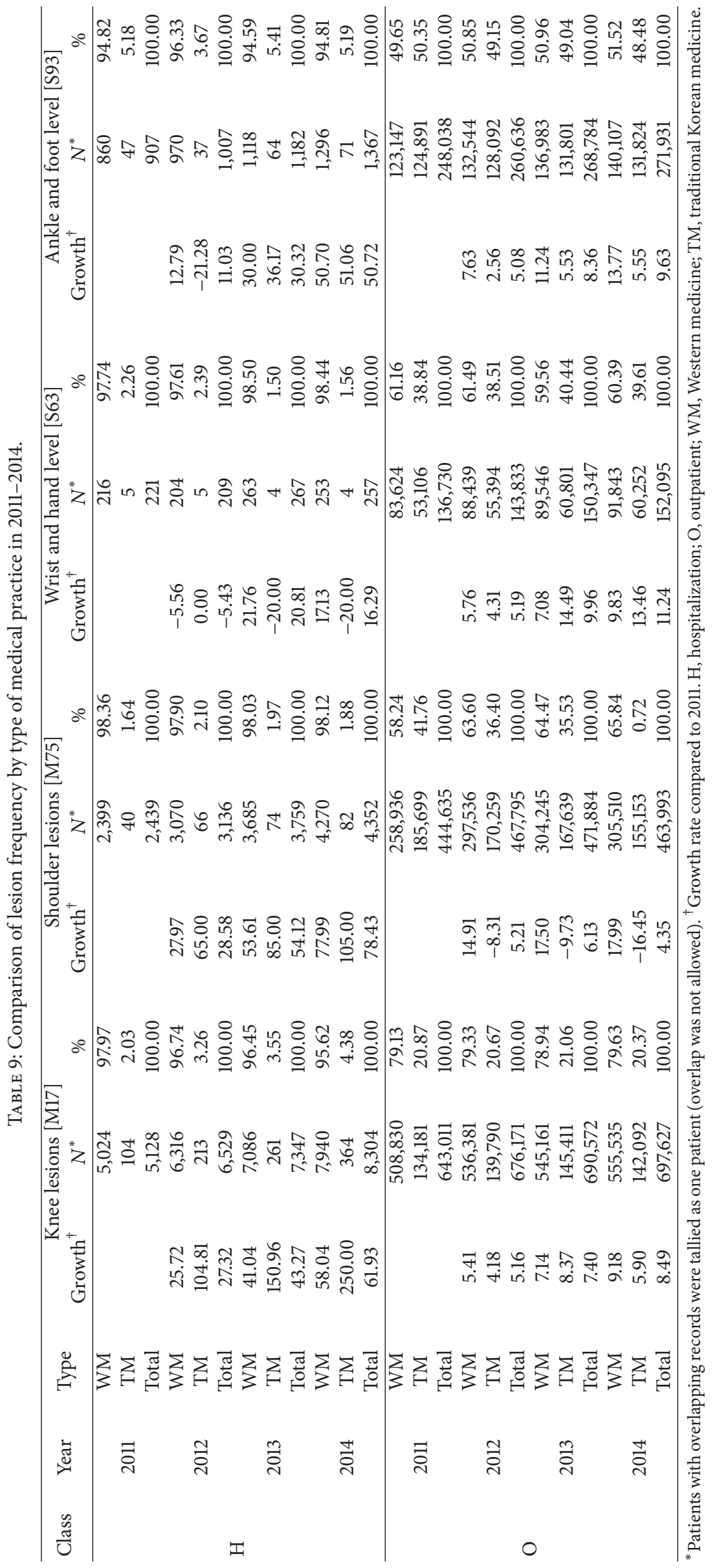


TABLE 10: Numbers of hospitalizations for gonarthrosis [M17] patients by hospital type.

\begin{tabular}{|c|c|c|c|c|c|c|c|c|}
\hline \multirow{2}{*}{ Year } & \multirow{2}{*}{$\begin{array}{l}\text { Type of } \\
\text { medicine }\end{array}$} & \multirow[b]{2}{*}{ Hospital type } & \multicolumn{2}{|c|}{ Frequency } & \multicolumn{3}{|c|}{ Hospitalization costs } & \multirow{2}{*}{$\begin{array}{c}\text { LOS } \\
\text { Days per } \\
\text { episode }^{\S}\end{array}$} \\
\hline & & & $N^{*}$ & $\%$ & $\operatorname{Cost}^{\dagger}$ & $\%$ & Per diem ${ }^{\ddagger}$ & \\
\hline \multirow{11}{*}{2011} & \multirow{7}{*}{ Western } & Tertiary Hospital & 204 & 3.98 & 1,225 & 9.50 & 460,420 & 14.20 \\
\hline & & General Hospital & 589 & 11.49 & 3,215 & 24.93 & 254,225 & 22.53 \\
\hline & & Hospital & 1,689 & 32.94 & 7,044 & 54.62 & 225,222 & 17.68 \\
\hline & & Long-term care hospital & 1,857 & 36.21 & 553 & 4.29 & 94,819 & 4.42 \\
\hline & & Western Clinic & 683 & 13.32 & 794 & 6.16 & 81,749 & 13.64 \\
\hline & & Public Health Hospital & 2 & 0.04 & 1 & 0.01 & 39,420 & 11.00 \\
\hline & & Total & 5,024 & 97.97 & 12,832 & 99.50 & 170,393 & 12.66 \\
\hline & \multirow{3}{*}{ Traditional } & Traditional Hospital & 99 & 1.93 & 62 & 0.48 & 57,349 & 13.10 \\
\hline & & Traditional Clinic & 5 & 0.10 & 2 & 0.02 & 33,235 & 13.80 \\
\hline & & Total & 104 & 2.03 & 64 & 0.50 & 56,190 & 13.13 \\
\hline & Total & & 5,128 & 100.00 & 12,896 & 100.00 & 168,077 & 12.67 \\
\hline \multirow{11}{*}{2012} & \multirow{7}{*}{ Western } & Tertiary Hospital & 187 & 2.86 & 1,190 & 8.81 & 490,276 & 14.06 \\
\hline & & General Hospital & 615 & 9.42 & 3,188 & 23.60 & 236,169 & 22.07 \\
\hline & & Hospital & 2,011 & 30.80 & 7,435 & 55.05 & 212,520 & 15.80 \\
\hline & & Long-term care hospital & 2,792 & 42.76 & 700 & 5.18 & 99,643 & 3.50 \\
\hline & & Western Clinic & 710 & 10.87 & 868 & 6.42 & 78,343 & 13.69 \\
\hline & & Public Health Hospital & 1 & 0.02 & 1 & 0.01 & 42,477 & 19.00 \\
\hline & & Total & 6,316 & 96.74 & 13,383 & 99.08 & 158,039 & 10.69 \\
\hline & \multirow{3}{*}{ Traditional } & Traditional Hospital & 190 & 2.91 & 114 & 0.84 & 62,827 & 12.07 \\
\hline & & Traditional Clinic & 23 & 0.35 & 11 & 0.08 & 33,646 & 15.57 \\
\hline & & Total & 213 & 3.26 & 125 & 0.92 & 59,676 & 12.45 \\
\hline & Total & & 6,529 & 100.00 & 13,507 & 100.00 & 154,830 & 10.74 \\
\hline \multirow{11}{*}{2013} & \multirow{7}{*}{ Western } & Tertiary Hospital & 195 & 2.65 & 1,287 & 8.79 & 454,263 & 16.49 \\
\hline & & General Hospital & 725 & 9.87 & 3,681 & 25.16 & 234,228 & 21.27 \\
\hline & & Hospital & 1,997 & 27.18 & 7,678 & 52.49 & 215,432 & 16.46 \\
\hline & & Long-term care hospital & 3,393 & 46.18 & 888 & 6.07 & 98,884 & 3.62 \\
\hline & & Western Clinic & 774 & 10.53 & 939 & 6.42 & 84,784 & 12.97 \\
\hline & & Public Health Hospital & 2 & 0.03 & 1 & 0.01 & 44,311 & 16.00 \\
\hline & & Total & 7,086 & 96.45 & 14,474 & 98.95 & 153,802 & 10.42 \\
\hline & \multirow{3}{*}{ Traditional } & Traditional Hospital & 234 & 3.18 & 140 & 0.96 & 64,218 & 11.45 \\
\hline & & Traditional Clinic & 27 & 0.37 & 14 & 0.10 & 42,487 & 13.56 \\
\hline & & Total & 261 & 3.55 & 154 & 1.05 & 61,970 & 11.67 \\
\hline & Total & & 7,347 & 100.00 & 14,628 & 100.00 & 150,539 & 10.47 \\
\hline \multirow{11}{*}{2014} & \multirow{7}{*}{ Western } & Tertiary Hospital & 272 & 3.28 & 1,641 & 11.46 & 459,732 & 14.81 \\
\hline & & General Hospital & 727 & 8.75 & 3,723 & 26.01 & 233,047 & 22.00 \\
\hline & & Hospital & 2,152 & 25.92 & 6,911 & 48.29 & 205,374 & 14.52 \\
\hline & & Long-term care hospital & 4,022 & 48.43 & 1,045 & 7.30 & 102,035 & 3.44 \\
\hline & & Western Clinic & 766 & 9.22 & 783 & 5.47 & 75,945 & 13.00 \\
\hline & & Public Health Hospital & 1 & 0.01 & 0 & 0.00 & 63,640 & 4.00 \\
\hline & & Total & 7,940 & 95.62 & 14,103 & 98.54 & 151,771 & 9.46 \\
\hline & \multirow{3}{*}{ Traditional } & Traditional Hospital & 329 & 3.96 & 193 & 1.35 & 64,804 & 11.00 \\
\hline & & Traditional Clinic & 35 & 0.42 & 16 & 0.11 & 38,910 & 13.77 \\
\hline & & Total & 364 & 4.38 & 209 & 1.46 & 62,314 & 11.26 \\
\hline & Total & & 8,304 & 100.00 & 14,312 & 100.00 & 147,849 & 9.54 \\
\hline
\end{tabular}

${ }^{*}$ Patients with overlapping records were tallied as one patient (overlap was not allowed). ${ }^{\dagger}$ Costs determined to be eligible for reimbursement by the HIRA (Health Insurance Review and Assessment Service) out of the total treatment amount were indicated in the submitted insurance claim statement. They are expressed as means and are in Korean Won $(1,000,000 \mathrm{KRW}) .{ }^{\ddagger}$ Per diem is the average daily cost of services covered by National Health Insurance. ${ }^{\S}$ Days per episode are the total number of hospitalized days divided by the total number of hospitalizations. 
TABLE 11: Number of outpatients with gonarthrosis [M17] by hospital type.

\begin{tabular}{|c|c|c|c|c|c|c|c|c|}
\hline \multirow[b]{2}{*}{ Year } & \multirow{2}{*}{$\begin{array}{l}\text { Type of } \\
\text { medicine }\end{array}$} & \multirow[b]{2}{*}{ Hospital type } & \multicolumn{2}{|c|}{ Frequency } & \multicolumn{3}{|c|}{ Outpatient costs } & \multirow{2}{*}{$\begin{array}{c}\text { LOS } \\
\text { Days per } \\
\text { episode }\end{array}$} \\
\hline & & & $N^{*}$ & $\%$ & $\operatorname{Cost}^{\dagger}$ & $\%$ & Per diem ${ }^{\ddagger}$ & \\
\hline \multirow{13}{*}{2011} & \multirow{9}{*}{ Western } & Tertiary Hospital & 3,771 & 0.59 & 199 & 1.35 & 39,490 & 1.76 \\
\hline & & General Hospital & 13,999 & 2.18 & 689 & 4.69 & 32,279 & 6.26 \\
\hline & & Hospital & 28,259 & 4.39 & 1,667 & 11.33 & 28,169 & 2.04 \\
\hline & & Long-term care hospital & 1,872 & 0.29 & 95 & 0.65 & 15,504 & 3.51 \\
\hline & & Clinic & 458,027 & 71.23 & 9,641 & 65.55 & 21,049 & 1.02 \\
\hline & & Public Health Center & 1,495 & 0.23 & 5 & 0.04 & 3,474 & 1.00 \\
\hline & & Local Public Health Clinic & 389 & 0.06 & 5 & 0.03 & 12,991 & 7.70 \\
\hline & & Public Health Hospital & 1,018 & 0.16 & 27 & 0.18 & 26,723 & 1.67 \\
\hline & & Total & 508,830 & 79.13 & 12,329 & 83.83 & 21,823 & 1.24 \\
\hline & \multirow{3}{*}{ Traditional } & Traditional Hospital & 1,022 & 0.16 & 49 & 0.33 & 16,099 & 2.81 \\
\hline & & Traditional Clinic & 133,159 & 20.71 & 2,330 & 15.84 & 17,497 & 1.04 \\
\hline & & Total & 134,181 & 20.87 & 2,379 & 16.17 & 17,486 & 1.05 \\
\hline & Total & & 643,011 & 100.00 & 14,707 & 100.00 & 20,918 & 1.20 \\
\hline \multirow{14}{*}{2012} & \multirow{10}{*}{ Western } & Tertiary Hospital & 4,817 & 0.71 & 215 & 1.42 & 44,547 & 1.55 \\
\hline & & General Hospital & 20,949 & 3.10 & 720 & 4.76 & 34,367 & 4.58 \\
\hline & & Hospital & 54,982 & 8.13 & 1,858 & 12.27 & 33,789 & 1.12 \\
\hline & & Long-term care hospital & 4,519 & 0.67 & 99 & 0.66 & 22,003 & 1.42 \\
\hline & & Clinic & 448,226 & 66.29 & 9,691 & 64.01 & 21,621 & 1.02 \\
\hline & & Public Health Center & 1,592 & 0.00 & 6 & 0.00 & 3,811 & 1.01 \\
\hline & & Local Public Health Clinic & 439 & 0.24 & 3 & 0.04 & 7,361 & 4.12 \\
\hline & & Public Health Hospital & 855 & 0.06 & 26 & 0.02 & 30,431 & 1.46 \\
\hline & & Dental Hospital & 2 & 0.13 & 0 & 0.17 & 24,970 & 1.00 \\
\hline & & Total & 536,381 & 79.33 & 12,618 & 83.34 & 23,525 & 1.18 \\
\hline & \multirow{3}{*}{ Traditional } & Traditional Hospital & 2,332 & 0.34 & 50 & 0.33 & 21,369 & 1.16 \\
\hline & & Traditional Clinic & 137,458 & 20.33 & 2,472 & 16.33 & 17,986 & 1.03 \\
\hline & & Total & 139,790 & 20.67 & 2,522 & 16.66 & 18,042 & 1.03 \\
\hline & Total & & 676,171 & 100.00 & 15,140 & 100.00 & 22,391 & 1.15 \\
\hline \multirow{13}{*}{2013} & \multirow{9}{*}{ Western } & Tertiary Hospital & 4,949 & 0.72 & 218 & 1.37 & 44,048 & 1.57 \\
\hline & & General Hospital & 21,512 & 3.12 & 783 & 4.92 & 36,416 & 4.20 \\
\hline & & Hospital & 55,199 & 7.99 & 1,879 & 11.81 & 34,034 & 1.12 \\
\hline & & Long-term care hospital & 4,780 & 0.69 & 104 & 0.66 & 21,854 & 1.49 \\
\hline & & Clinic & 456,160 & 66.06 & 10,203 & 64.13 & 22,367 & 1.01 \\
\hline & & Public Health Center & 1,678 & 0.24 & 6 & 0.04 & 3,442 & 1.05 \\
\hline & & Local Public Health Clinic & 191 & 0.03 & 2 & 0.02 & 12,633 & 6.90 \\
\hline & & Public Health Hospital & 692 & 0.10 & 23 & 0.15 & 33,579 & 1.97 \\
\hline & & Total & 545,161 & 78.94 & 13,219 & 83.09 & 24,248 & 1.16 \\
\hline & \multirow{3}{*}{ Traditional } & Traditional Hospital & 2,306 & 0.33 & 52 & 0.32 & 22,375 & 1.13 \\
\hline & & Traditional Clinic & 143,105 & 20.72 & 2,639 & 16.59 & 18,443 & 1.03 \\
\hline & & Total & 145,411 & 21.06 & 2,691 & 16.91 & 18,505 & 1.03 \\
\hline & Total & & 690,572 & 100.00 & 15,910 & 100.00 & 23,039 & 1.14 \\
\hline \multirow{14}{*}{2014} & \multirow{11}{*}{ Western } & Tertiary Hospital & 5,377 & 0.77 & 243 & 1.43 & 45,133 & 1.24 \\
\hline & & General Hospital & 22,999 & 3.30 & 856 & 5.06 & 37,234 & 3.85 \\
\hline & & Hospital & 57,441 & 8.23 & 1,986 & 11.74 & 34,571 & 1.11 \\
\hline & & Long-term care hospital & 4,748 & 0.68 & 106 & 0.63 & 22,320 & 1.48 \\
\hline & & Clinic & 461,684 & 66.18 & 10,962 & 64.81 & 23,742 & 1.01 \\
\hline & & Public Health Center & 2,372 & 0.00 & 8 & 0.00 & 3,298 & 1.00 \\
\hline & & Local Public Health Clinic & 171 & 0.34 & 2 & 0.05 & 12,230 & 6.67 \\
\hline & & Public Health Hospital & 732 & 0.02 & 21 & 0.01 & 28,470 & 1.31 \\
\hline & & Dental Hospital & 11 & 0.10 & 0 & 0.12 & 18,469 & 1.00 \\
\hline & & Total & 555,535 & 79.63 & 14,183 & 83.86 & 25,531 & 1.15 \\
\hline & & Traditional Hospital & 2,516 & 0.36 & 59 & 0.35 & 23,541 & 1.13 \\
\hline & Traditional & Traditional Clinic & 139,576 & 20.01 & 2,670 & 15.79 & 19,127 & 1.03 \\
\hline & & Total & 142,092 & 20.37 & 2,729 & 16.14 & 19,205 & 1.03 \\
\hline & Total & & 697,627 & 100.00 & 16,912 & 100.00 & 24,242 & 1.12 \\
\hline
\end{tabular}

${ }^{*}$ Patients with overlapping records were tallied as one patient (overlap was not allowed). ${ }^{\dagger}$ Costs determined to be eligible for reimbursement by the HIRA (Health Insurance Review and Assessment Service) out of the total treatment amount were indicated in the submitted insurance claim statement. They is expressed as a mean and are in Korean Won $(1,000,000 \mathrm{KRW}) .{ }^{\ddagger}$ Per diem is the average daily cost of services covered by National Health Insurance. ${ }^{\S}$ Days per episode are the total number of outpatient visit days including drug prescription days divided by the total number of outpatient visits. 
TABLE 12: Number of hospitalizations for shoulder lesion [M75] patients by hospital type.

\begin{tabular}{|c|c|c|c|c|c|c|c|c|}
\hline \multirow[b]{2}{*}{ Year } & \multirow{2}{*}{$\begin{array}{l}\text { Type of } \\
\text { medicine }\end{array}$} & \multirow[b]{2}{*}{ Hospital type } & \multicolumn{2}{|c|}{ Frequency } & \multicolumn{3}{|c|}{ Hospitalization costs } & \multirow{2}{*}{$\begin{array}{c}\text { LOS } \\
\text { Days per } \\
\text { episode }^{\S}\end{array}$} \\
\hline & & & $N^{*}$ & $\%$ & $\operatorname{Cost}^{\dagger}$ & $\%$ & Per diem ${ }^{\ddagger}$ & \\
\hline \multirow{10}{*}{2011} & \multirow{6}{*}{ Western } & Tertiary Hospital & 135 & 5.54 & 278 & 9.55 & 377,378 & 6.08 \\
\hline & & General Hospital & 381 & 15.62 & 765 & 26.31 & 210,523 & 12.83 \\
\hline & & Hospital & 1,101 & 45.14 & 1,608 & 55.27 & 203,071 & 8.86 \\
\hline & & Long-term care hospital & 589 & 24.15 & 69 & 2.37 & 94,749 & 1.45 \\
\hline & & Western Clinic & 193 & 7.91 & 167 & 5.74 & 99,580 & 11.10 \\
\hline & & Total & 2,399 & 98.36 & 2,886 & 99.24 & 179,142 & 7.69 \\
\hline & \multirow{3}{*}{ Traditional } & Traditional Hospital & 39 & 1.6 & 22 & 0.75 & 53203 & 14.26 \\
\hline & & Traditional Clinic & 1 & 0.04 & 0 & 0.01 & 21440 & 14 \\
\hline & & Total & 40 & 1.64 & 22 & 0.76 & 52409 & 14.25 \\
\hline & Total & & 2,439 & 100.00 & 2,908 & 100.00 & 177,064 & 7.80 \\
\hline \multirow{10}{*}{2012} & \multirow{6}{*}{ Western } & Tertiary Hospital & 142 & 4.53 & 318 & 8.32 & 374,833 & 6.37 \\
\hline & & General Hospital & 468 & 14.92 & 989 & 25.85 & 208,846 & 12.43 \\
\hline & & Hospital & 1,547 & 49.33 & 2,168 & 56.66 & 200,108 & 8.36 \\
\hline & & Long-term care hospital & 661 & 21.08 & 75 & 1.96 & 98,519 & 1.25 \\
\hline & & Western Clinic & 252 & 8.04 & 242 & 6.33 & 138,525 & 9.81 \\
\hline & & Total & 3,070 & 97.90 & 3,792 & 99.13 & 182,594 & 7.48 \\
\hline & \multirow{3}{*}{ Traditional } & Traditional Hospital & 62 & 1.98 & 32 & 0.84 & 58,945 & 11.53 \\
\hline & & Traditional Clinic & 4 & 0.13 & 1 & 0.03 & 31,056 & 14.25 \\
\hline & & Total & 66 & 2.10 & 33 & 0.87 & 57,255 & 11.70 \\
\hline & Total & & 3,136 & 100.00 & 3,826 & 100.00 & 179,956 & 7.57 \\
\hline \multirow{11}{*}{2013} & \multirow{7}{*}{ Western } & Tertiary Hospital & 169 & 4.50 & 388 & 8.65 & 379,396 & 6.41 \\
\hline & & General Hospital & 582 & 15.48 & 1,212 & 27.01 & 188,152 & 13.07 \\
\hline & & Hospital & 1,920 & 51.08 & 2,524 & 56.27 & 193,851 & 7.58 \\
\hline & & Long-term care hospital & 739 & 19.66 & 100 & 2.22 & 95,331 & 1.68 \\
\hline & & Western Clinic & 274 & 7.29 & 223 & 4.97 & 156,193 & 8.29 \\
\hline & & Public Health Hospital & 1 & 0.03 & 0 & 0.00 & 89,370 & 1.00 \\
\hline & & Total & 3,685 & 98.03 & 4,446 & 99.12 & 178,875 & 7.26 \\
\hline & \multirow{3}{*}{ Traditional } & Traditional Hospital & 68 & 1.81 & 37 & 0.82 & 64,497 & 10.57 \\
\hline & & Traditional Clinic & 6 & 0.16 & 3 & 0.06 & 40,844 & 14.17 \\
\hline & & Total & 74 & 1.97 & 40 & 0.88 & 62,579 & 10.86 \\
\hline & Total & & 3,759 & 100.00 & 4,485 & 100.00 & 176,585 & 7.33 \\
\hline \multirow{10}{*}{2014} & \multirow{6}{*}{ Western } & Tertiary Hospital & 161 & 3.70 & 333 & 6.97 & 377,875 & 5.68 \\
\hline & & General Hospital & 671 & 15.42 & 1,214 & 25.45 & 202,746 & 10.41 \\
\hline & & Hospital & 2,298 & 52.80 & 2,773 & 58.12 & 188,633 & 6.86 \\
\hline & & Long-term care hospital & 817 & 18.77 & 134 & 2.80 & 99,291 & 2.07 \\
\hline & & Western Clinic & 323 & 7.42 & 276 & 5.79 & 164,902 & 8.50 \\
\hline & & Total & 4,270 & 98.12 & 4,730 & 99.12 & 179,097 & 6.58 \\
\hline & \multirow{3}{*}{ Traditional } & Traditional Hospital & 76 & 1.75 & 39 & 0.83 & 60,405 & 10.09 \\
\hline & & Traditional Clinic & 6 & 0.14 & 2 & 0.05 & 23,633 & 17.17 \\
\hline & & Total & 82 & 1.88 & 42 & 0.88 & 57,714 & 10.61 \\
\hline & Total & & 4,352 & 100.00 & 4,772 & 100.00 & 176,810 & 6.66 \\
\hline
\end{tabular}

${ }^{*}$ Patients with overlapping records were tallied as one patient (overlap not allowed). ${ }^{\dagger}$ Costs determined to be eligible for reimbursement by the HIRA (Health Insurance Review and Assessment Service) out of the total treatment amount were indicated in the submitted insurance claim statement. They are expressed as means and are in Korean Won $(1,000,000 \mathrm{KRW}) .{ }^{\ddagger}$ Per diem is the average daily cost of services covered by National Health Insurance. ${ }^{\S}$ Days per episode are the total number of hospitalized days divided by the total number of hospitalizations. 
TABLE 13: Number of outpatients with shoulder lesions [M75] by hospital type.

\begin{tabular}{|c|c|c|c|c|c|c|c|c|}
\hline \multirow[b]{2}{*}{ Year } & \multirow{2}{*}{$\begin{array}{l}\text { Type of } \\
\text { medicine }\end{array}$} & \multirow[b]{2}{*}{ Hospital type } & \multicolumn{2}{|c|}{ Frequency } & \multicolumn{3}{|c|}{ Outpatient costs } & \multirow{2}{*}{$\begin{array}{c}\text { LOS } \\
\text { Days per } \\
\text { episode }\end{array}$} \\
\hline & & & $N^{*}$ & $\%$ & $\operatorname{Cost}^{\dagger}$ & $\%$ & Per diem ${ }^{\ddagger}$ & \\
\hline \multirow{14}{*}{2011} & \multirow{10}{*}{ Western } & Tertiary Hospital & 3,279 & 0.74 & 147 & 1.55 & 29,079 & 2.14 \\
\hline & & General Hospital & 8,754 & 1.97 & 420 & 4.42 & 26,730 & 4.09 \\
\hline & & Hospital & 16,434 & 3.70 & 803 & 8.45 & 21,712 & 2.21 \\
\hline & & Long-term care hospital & 1,120 & 0.25 & 47 & 0.50 & 16,906 & 2.84 \\
\hline & & Clinic & 228,892 & 51.48 & 4,559 & 47.99 & 19,916 & 1.01 \\
\hline & & Dental Hospital & 8 & 0.00 & 0 & 0.00 & 18,765 & 1.63 \\
\hline & & Public Health Center & 301 & 0.07 & 1 & 0.01 & 3,204 & 1.00 \\
\hline & & Local Public Health Clinic & 22 & 0.00 & 0 & 0.00 & 5,281 & 1.91 \\
\hline & & Public Health Hospital & 126 & 0.03 & 3 & 0.03 & 23,603 & 1.25 \\
\hline & & Total & 258,936 & 58.24 & 5,980 & 62.96 & 20,345 & 1.21 \\
\hline & \multirow{3}{*}{ Traditional } & Traditional Hospital & 1,327 & 0.30 & 62 & 0.66 & 17,637 & 2.58 \\
\hline & & Traditional Clinic & 184,372 & 41.47 & 3,456 & 36.39 & 18,746 & 1.04 \\
\hline & & Total & 185,699 & 41.76 & 3,519 & 37.04 & 18,738 & 1.05 \\
\hline & Total & & 444,635 & 100.00 & 9,499 & 100.00 & 19,674 & 1.14 \\
\hline \multirow{14}{*}{2012} & \multirow{10}{*}{ Western } & Tertiary Hospital & 4,805 & 1.03 & 150 & 1.54 & 31,203 & 1.33 \\
\hline & & General Hospital & 16,148 & 3.45 & 418 & 4.29 & 25,911 & 2.07 \\
\hline & & Hospital & 42,956 & 9.18 & 1,004 & 10.29 & 23,362 & 1.05 \\
\hline & & Long-term care hospital & 2,372 & 0.51 & 52 & 0.53 & 21,931 & 1.40 \\
\hline & & Clinic & 230,518 & 49.28 & 4,790 & 49.14 & 20,780 & 1.01 \\
\hline & & Dental Hospital & 5 & 0.00 & 0 & 0.00 & 26,800 & 1.00 \\
\hline & & Public Health Center & 552 & 0.12 & 2 & 0.02 & 3,290 & 1.00 \\
\hline & & Local Public Health Clinic & 12 & 0.00 & 0 & 0.00 & 9,058 & 3.92 \\
\hline & & Public Health Hospital & 168 & 0.04 & 4 & 0.04 & 22,856 & 3.33 \\
\hline & & Total & 297,536 & 63.60 & 6,420 & 65.85 & 21,577 & 1.08 \\
\hline & \multirow{3}{*}{ Traditional } & Traditional Hospital & 2,348 & 0.50 & 52 & 0.53 & 22,053 & 1.31 \\
\hline & & Traditional Clinic & 167,911 & 35.89 & 3,277 & 33.62 & 19,517 & 1.03 \\
\hline & & Total & 170,259 & 36.40 & 3,329 & 34.15 & 19,552 & 1.04 \\
\hline & Total & & 467,795 & 100.00 & 9,749 & 100.00 & 20,840 & 1.07 \\
\hline \multirow{14}{*}{2013} & \multirow{10}{*}{ Western } & Tertiary Hospital & 5,053 & 1.07 & 167 & 1.63 & 33,032 & 1.29 \\
\hline & & General Hospital & 15,611 & 3.31 & 434 & 4.26 & 27,831 & 2.06 \\
\hline & & Hospital & 46,514 & 9.86 & 1,108 & 10.85 & 23,823 & 1.05 \\
\hline & & Long-term care hospital & 2,105 & 0.45 & 49 & 0.48 & 23,288 & 1.45 \\
\hline & & Clinic & 234,099 & 49.61 & 5,077 & 49.73 & 21,688 & 1.01 \\
\hline & & Dental Hospital & 6 & 0.00 & 0 & 0.00 & 17,590 & 1.00 \\
\hline & & Public Health Center & 701 & 0.15 & 2 & 0.02 & 2,487 & 1.00 \\
\hline & & Local Public Health Clinic & 24 & 0.01 & 0 & 0.00 & 6,914 & 2.96 \\
\hline & & Public Health Hospital & 132 & 0.03 & 3 & 0.03 & 25,864 & 1.74 \\
\hline & & Total & 304,245 & 64.47 & 6,841 & 67.01 & 22,486 & 1.08 \\
\hline & \multirow{3}{*}{ Traditional } & Traditional Hospital & 2,163 & 0.46 & 51 & 0.50 & 23,727 & 1.09 \\
\hline & & Traditional Clinic & 165,476 & 35.07 & 3,317 & 32.49 & 20,047 & 1.03 \\
\hline & & Total & 167,639 & 35.53 & 3,369 & 32.99 & 20,095 & 1.03 \\
\hline & Total & & 471,884 & 100.00 & 10,210 & 100.00 & 21,636 & 1.06 \\
\hline \multirow{13}{*}{2014} & & Tertiary Hospital & 4,474 & 0.96 & 149 & 1.42 & 33,281 & 1.34 \\
\hline & & General Hospital & 17,733 & 3.82 & 502 & 4.79 & 28,320 & 2.11 \\
\hline & & Hospital & 48,171 & 10.38 & 1,136 & 10.85 & 23,590 & 1.04 \\
\hline & & Long-term care hospital & 2,106 & 0.45 & 50 & 0.47 & 23,507 & 1.36 \\
\hline & Western & Clinic & 232,309 & 50.07 & 5,315 & 50.74 & 22,881 & 1.01 \\
\hline & & Public Health Center & 471 & 0.10 & 2 & 0.02 & 3,848 & 1.37 \\
\hline & & Local Public Health Clinic & 35 & 0.01 & 0 & 0.00 & 7,430 & 3.80 \\
\hline & & Public Health Hospital & 211 & 0.05 & 6 & 0.06 & 28,187 & 1.34 \\
\hline & & Total & 305,510 & 65.84 & 7,160 & 68.35 & 23,437 & 1.09 \\
\hline & & Traditional Hospital & 3,330 & 33.44 & 73 & 30.96 & 21,781 & 1.03 \\
\hline & Traditional & Traditional Clinic & 155,153 & 0.72 & 3,243 & 0.69 & 20,903 & 1.03 \\
\hline & & Total & 158,483 & 34.16 & 3,316 & 31.65 & 20,921 & 1.03 \\
\hline & Total & & 463,993 & 100.00 & 10,476 & 100.00 & 22,578 & 1.07 \\
\hline
\end{tabular}

${ }^{*}$ Patients with overlapping records were tallied as one patient (overlap was not allowed). ${ }^{\dagger}$ Costs determined to be eligible for reimbursement by the HIRA (Health Insurance Review and Assessment Service) out of the total treatment amount were indicated in the submitted insurance claim statement. They are expressed as means and are in Korean Won $(1,000,000 \mathrm{KRW}) .{ }^{\ddagger}$ Per diem is the average daily cost of services covered by National Health Insurance. ${ }^{\S}$ Days per episode are the total number of outpatient visit days including drug prescription days divided by the total number of outpatient visits. 
TABLE 14: Number of hospitalizations for wrist and hand level lesions [S63] by hospital type.

\begin{tabular}{|c|c|c|c|c|c|c|c|c|}
\hline \multirow{2}{*}{ Year } & \multirow{2}{*}{$\begin{array}{l}\text { Type of } \\
\text { medicine }\end{array}$} & \multirow[b]{2}{*}{ Hospital type } & \multicolumn{2}{|c|}{ Frequency } & \multicolumn{3}{|c|}{ Hospitalization costs } & \multirow{2}{*}{$\begin{array}{c}\text { LOS } \\
\text { Days per } \\
\text { episode }^{\S}\end{array}$} \\
\hline & & & $N^{*}$ & $\%$ & $\operatorname{Cost}^{\dagger}$ & $\%$ & Per diem ${ }^{\ddagger}$ & \\
\hline \multirow{10}{*}{2011} & \multirow{6}{*}{ Western } & Tertiary Hospital & 11 & 4.98 & 13 & 7.68 & 278,227 & 5.45 \\
\hline & & General Hospital & 45 & 20.36 & 43 & 25.65 & 179,511 & 6.20 \\
\hline & & Hospital & 97 & 43.89 & 74 & 44.40 & 139,886 & 6.36 \\
\hline & & Long-term care hospital & 11 & 4.98 & 1 & 0.84 & 61,642 & 2.18 \\
\hline & & Western Clinic & 52 & 23.53 & 34 & 20.56 & 82,895 & 9.83 \\
\hline & & Total & 216 & 97.74 & 165 & 99.13 & 137,482 & 6.90 \\
\hline & \multirow{3}{*}{ Traditional } & Traditional Hospital & 4 & 1.81 & 1 & 0.59 & 50,891 & 4.75 \\
\hline & & Traditional Clinic & 1 & 0.45 & 0 & 0.28 & 32,616 & 14.00 \\
\hline & & Total & 5 & 2.26 & 1 & 0.87 & 47,236 & 6.60 \\
\hline & Total & & 221 & 100.00 & 166 & 100.00 & 135,440 & 6.90 \\
\hline \multirow{10}{*}{2012} & \multirow{6}{*}{ Western } & Tertiary Hospital & 9 & 4.31 & 10 & 6.32 & 248,187 & 4.89 \\
\hline & & General Hospital & 32 & 15.31 & 31 & 20.03 & 181,560 & 8.19 \\
\hline & & Hospital & 112 & 53.59 & 87 & 55.96 & 127,213 & 7.51 \\
\hline & & Long-term care hospital & 13 & 6.22 & 1 & 0.83 & 99,160 & 1.00 \\
\hline & & Western Clinic & 38 & 18.18 & 25 & 15.80 & 91,169 & 9.32 \\
\hline & & Total & 204 & 97.61 & 154 & 98.93 & 132,573 & 7.42 \\
\hline & \multirow{3}{*}{ Traditional } & Traditional Hospital & 2 & 0.96 & 1 & 0.61 & 53,661 & 8.00 \\
\hline & & Traditional Clinic & 3 & 1.44 & 1 & 0.46 & 41,900 & 7.33 \\
\hline & & Total & 5 & 2.39 & 2 & 1.07 & 46,604 & 7.60 \\
\hline & Total & & 209 & 100.00 & 156 & 100.00 & 130,517 & 7.43 \\
\hline \multirow{9}{*}{2013} & \multirow{6}{*}{ Western } & Tertiary Hospital & 11 & 4.12 & 13 & 7.25 & 342,630 & 3.73 \\
\hline & & General Hospital & 50 & 18.73 & 47 & 26.27 & 156,802 & 6.76 \\
\hline & & Hospital & 111 & 41.57 & 85 & 46.85 & 130,977 & 6.95 \\
\hline & & Long-term care hospital & 44 & 16.48 & 4 & 1.98 & 80,871 & 1.09 \\
\hline & & Western Clinic & 47 & 17.60 & 30 & 16.67 & 88,549 & 10.30 \\
\hline & & Total & 263 & 98.50 & 179 & 99.03 & 128,774 & 6.40 \\
\hline & \multirow{2}{*}{ Traditional } & Traditional Hospital & 4 & 1.50 & 2 & 0.97 & 53,481 & 8.00 \\
\hline & & Total & 4 & 1.50 & 2 & 0.97 & 53,481 & 8.00 \\
\hline & Total & & 267 & 100.00 & 180 & 100.00 & 127,646 & 6.42 \\
\hline \multirow{10}{*}{2014} & \multirow{6}{*}{ Western } & Tertiary Hospital & 13 & 5.06 & 12 & 5.82 & 210,379 & 4.00 \\
\hline & & General Hospital & 65 & 25.29 & 71 & 33.81 & 167,548 & 8.48 \\
\hline & & Hospital & 118 & 45.91 & 97 & 46.30 & 137,949 & 6.69 \\
\hline & & Long-term care hospital & 14 & 5.45 & 1 & 0.54 & 81,609 & 1.00 \\
\hline & & Western Clinic & 43 & 16.73 & 27 & 12.62 & 88,134 & 8.91 \\
\hline & & Total & 253 & 98.44 & 208 & 99.08 & 137,691 & 7.08 \\
\hline & \multirow{3}{*}{ Traditional } & Traditional Hospital & 3 & 1.17 & 1 & 0.59 & 64,672 & 8.00 \\
\hline & & Traditional Clinic & 1 & 0.39 & 1 & 0.33 & 36,168 & 19.00 \\
\hline & & Total & 4 & 1.56 & 2 & 0.92 & 57,546 & 10.75 \\
\hline & Total & & 257 & 100.00 & 210 & 100.00 & 136,444 & 7.13 \\
\hline
\end{tabular}

${ }^{*}$ Patients with overlapping records were tallied as one patient (overlap was not allowed). ${ }^{\dagger}$ Costs determined to be eligible for reimbursement by the HIRA (Health Insurance Review and Assessment Service) out of the total treatment amount were indicated in the submitted insurance claim statement. They are expressed as means and are in Korean Won $(1,000,000 \mathrm{KRW}) .{ }^{\ddagger}$ Per diem is the average daily cost of services covered by National Health Insurance. ${ }^{\$}$ Days per episode are the total number of hospitalized days divided by the total number of hospitalizations. 
TABLE 15: Number of outpatients for wrist and hand level lesions [S63] by hospital type.

\begin{tabular}{|c|c|c|c|c|c|c|c|c|}
\hline \multirow[b]{2}{*}{ Year } & \multirow{2}{*}{$\begin{array}{l}\text { Type of } \\
\text { medicine }\end{array}$} & \multirow[b]{2}{*}{ Hospital type } & \multicolumn{2}{|c|}{ Frequency } & \multicolumn{3}{|c|}{ Outpatient costs } & \multirow{2}{*}{$\begin{array}{c}\text { LOS } \\
\text { Days per } \\
\text { episode }\end{array}$} \\
\hline & & & $N^{*}$ & $\%$ & $\operatorname{Cost}^{\dagger}$ & $\%$ & Per $\operatorname{diem}^{\ddagger}$ & \\
\hline \multirow{13}{*}{2011} & \multirow{9}{*}{ Western } & Tertiary Hospital & 251 & 0.18 & 19 & 0.60 & 58,745 & 1.58 \\
\hline & & General Hospital & 2,612 & 1.91 & 155 & 4.95 & 44,742 & 1.62 \\
\hline & & Hospital & 7,082 & 5.18 & 319 & 10.18 & 29,974 & 1.58 \\
\hline & & Long-term care hospital & 321 & 0.23 & 12 & 0.37 & 18,678 & 1.99 \\
\hline & & Clinic & 73,276 & 53.59 & 1,618 & 51.67 & 22,082 & 1.00 \\
\hline & & Public Health Center & 39 & 0.03 & 0 & 0.01 & 5,699 & 1.00 \\
\hline & & Local Public Health Clinic & 13 & 0.01 & 0 & 0.01 & 18,520 & 11.46 \\
\hline & & Public Health Hospital & 30 & 0.02 & 1 & 0.02 & 18,767 & 1.23 \\
\hline & & Total & 83,624 & 61.16 & 2,124 & 67.81 & 23,546 & 1.08 \\
\hline & \multirow{3}{*}{ Traditional } & Traditional Hospital & 545 & 0.40 & 21 & 0.68 & 18,048 & 2.18 \\
\hline & & Traditional Clinic & 52,561 & 38.44 & 987 & 31.51 & 18,777 & 1.03 \\
\hline & & Total & 53,106 & 38.84 & 1,008 & 32.19 & 18,770 & 1.04 \\
\hline & Total & & 136,730 & 100.00 & 3,132 & 100.00 & 21,691 & 1.06 \\
\hline \multirow{13}{*}{2012} & \multirow{9}{*}{ Western } & Tertiary Hospital & 306 & 0.21 & 16 & 0.48 & 51,987 & 1.36 \\
\hline & & General Hospital & 3,404 & 2.37 & 146 & 4.41 & 42,810 & 1.19 \\
\hline & & Hospital & 11,477 & 7.98 & 357 & 10.80 & 31,071 & 1.04 \\
\hline & & Long-term care hospital & 667 & 0.46 & 13 & 0.40 & 19,954 & 1.10 \\
\hline & & Clinic & 72,525 & 50.42 & 1,680 & 50.86 & 23,163 & 1.01 \\
\hline & & Public Health Center & 1 & 0.00 & 0 & 0.00 & 5,790 & 1.00 \\
\hline & & Local Public Health Clinic & 13 & 0.01 & 0 & 0.00 & 8,726 & 4.00 \\
\hline & & Public Health Hospital & 46 & 0.03 & 1 & 0.04 & 29,252 & 1.43 \\
\hline & & Total & 88,439 & 61.49 & 2,213 & 66.99 & 25,022 & 1.02 \\
\hline & \multirow{3}{*}{ Traditional } & Traditional Hospital & 838 & 0.58 & 18 & 0.53 & 20,947 & 1.05 \\
\hline & & Traditional Clinic & 54,556 & 37.93 & 1,073 & 32.48 & 19,664 & 1.02 \\
\hline & & Total & 55,394 & 38.51 & 1,090 & 33.01 & 19,683 & 1.02 \\
\hline & Total & & 143,833 & 100.00 & 3,303 & 100.00 & 22,966 & 1.02 \\
\hline \multirow{14}{*}{2013} & \multirow{10}{*}{ Western } & Tertiary Hospital & 297 & 0.20 & 19 & 0.54 & 65,123 & 1.40 \\
\hline & & General Hospital & 3,512 & 2.34 & 163 & 4.58 & 46,354 & 1.19 \\
\hline & & Hospital & 10,971 & 7.30 & 360 & 10.13 & 32,801 & 1.07 \\
\hline & & Long-term care hospital & 484 & 0.32 & 10 & 0.28 & 20,811 & 1.07 \\
\hline & & Clinic & 74,188 & 49.34 & 1,758 & 49.50 & 23,690 & 1.00 \\
\hline & & Public Health Center & 34 & 0.00 & 0 & 0.00 & 3,086 & 1.00 \\
\hline & & Local Public Health Clinic & 7 & 0.02 & 0 & 0.00 & 7,674 & 3.00 \\
\hline & & Public Health Hospital & 52 & 0.00 & 1 & 0.00 & 24,083 & 1.23 \\
\hline & & Dental Hospital & 1 & 0.03 & 0 & 0.04 & 24,540 & 1.00 \\
\hline & & Total & 89,546 & 59.56 & 2,311 & 65.09 & 25,808 & 1.02 \\
\hline & \multirow{3}{*}{ Traditional } & Traditional Hospital & 956 & 0.64 & 22 & 0.62 & 22,855 & 1.05 \\
\hline & & Traditional Clinic & 59,845 & 39.80 & 1,218 & 34.30 & 20,350 & 1.02 \\
\hline & & Total & 60,801 & 40.44 & 1,240 & 34.91 & 20,390 & 1.02 \\
\hline & Total & & 150,347 & 100.00 & 3,551 & 100.00 & 23,617 & 1.02 \\
\hline \multirow{14}{*}{2014} & \multirow{11}{*}{ Western } & Tertiary Hospital & 332 & 0.22 & 21 & 0.57 & 63,661 & 1.34 \\
\hline & & General Hospital & 3,886 & 2.55 & 180 & 4.80 & 46,221 & 1.44 \\
\hline & & Hospital & 11,366 & 7.47 & 372 & 9.96 & 32,755 & 1.05 \\
\hline & & Long-term care hospital & 646 & 0.42 & 14 & 0.38 & 21,995 & 1.20 \\
\hline & & Clinic & 75,535 & 49.66 & 1,868 & 49.94 & 24,725 & 1.00 \\
\hline & & Public Health Center & 10 & 0.00 & 0 & 0.00 & 4,050 & 1.00 \\
\hline & & Local Public Health Clinic & 14 & 0.01 & 0 & 0.00 & 8,487 & 3.43 \\
\hline & & Public Health Hospital & 50 & 0.01 & 1 & 0.00 & 24,903 & 1.18 \\
\hline & & Dental Hospital & 4 & 0.03 & 0 & 0.03 & 19,768 & 1.00 \\
\hline & & Total & 91,843 & 60.39 & 2,456 & 65.69 & 26,745 & 1.03 \\
\hline & & Traditional Hospital & 892 & 0.59 & 20 & 0.55 & 22,893 & 1.08 \\
\hline & Traditional & Traditional Clinic & 59,360 & 39.03 & 1,263 & 33.77 & 21,273 & 1.02 \\
\hline & & Total & 60,252 & 39.61 & 1,283 & 34.31 & 21,297 & 1.02 \\
\hline & Total & & 152,095 & 100.00 & 3,740 & 100.00 & 24,587 & 1.03 \\
\hline
\end{tabular}

${ }^{*}$ Patients with overlapping records were tallied as one patient (overlap was not allowed). ${ }^{\dagger}$ Costs determined to be eligible for reimbursement by the HIRA (Health Insurance Review and Assessment Service) out of the total treatment amount were indicated in the submitted insurance claim statement. They are expressed as means and are in Korean Won $(1,000,000 \mathrm{KRW}) .{ }^{\ddagger}$ Per diem is the average daily cost of services covered by National Health Insurance. ${ }^{\S}$ Days per episode are the total number of outpatient visit days including drug prescription days divided by the total number of outpatient visits. 
TABLE 16: Number of hospitalizations for ankle and foot level lesions [S93] by hospital type.

\begin{tabular}{|c|c|c|c|c|c|c|c|c|}
\hline \multirow{2}{*}{ Year } & \multirow{2}{*}{$\begin{array}{l}\text { Type of } \\
\text { medicine }\end{array}$} & \multirow[b]{2}{*}{ Hospital type } & \multicolumn{2}{|c|}{ Frequency } & \multicolumn{3}{|c|}{ Hospitalization costs } & \multirow{2}{*}{$\begin{array}{c}\text { LOS } \\
\text { Days per } \\
\text { episode }\end{array}$} \\
\hline & & & $N^{*}$ & $\%$ & $\operatorname{Cost}^{\dagger}$ & $\%$ & Per diem ${ }^{\ddagger}$ & \\
\hline \multirow{10}{*}{2011} & \multirow{6}{*}{ Western } & Tertiary Hospital & 5 & 0.55 & 8 & 1.24 & 173,270 & 10.40 \\
\hline & & General Hospital & 108 & 11.91 & 123 & 18.23 & 98,380 & 12.77 \\
\hline & & Hospital & 345 & 38.04 & 280 & 41.41 & 84,468 & 10.59 \\
\hline & & Long-term care hospital & 34 & 3.75 & 6 & 0.96 & 65,373 & 3.26 \\
\hline & & Western Clinic & 368 & 40.57 & 241 & 35.54 & 56,559 & 12.45 \\
\hline & & Total & 860 & 94.82 & 659 & 97.38 & 74,034 & 11.37 \\
\hline & \multirow{3}{*}{ Traditional } & Traditional Hospital & 42 & 4.63 & 17 & 2.47 & 49,012 & 9.38 \\
\hline & & Traditional Clinic & 5 & 0.55 & 1 & 0.15 & 34,441 & 6.80 \\
\hline & & Total & 47 & 5.18 & 18 & 2.62 & 47,462 & 9.11 \\
\hline & Total & & 907 & 100.00 & 677 & 100.00 & 72,657 & 11.25 \\
\hline \multirow{10}{*}{2012} & \multirow{6}{*}{ Western } & Tertiary Hospital & 10 & 0.99 & 12 & 1.61 & 193,439 & 6.00 \\
\hline & & General Hospital & 148 & 14.70 & 156 & 20.70 & 108,791 & 11.49 \\
\hline & & Hospital & 391 & 38.83 & 305 & 40.51 & 88,346 & 9.74 \\
\hline & & Long-term care hospital & 38 & 3.77 & 12 & 1.61 & 82,398 & 5.34 \\
\hline & & Western Clinic & 383 & 38.03 & 250 & 33.20 & 59,570 & 11.50 \\
\hline & & Total & 970 & 96.33 & 734 & 97.63 & 80,954 & 10.49 \\
\hline & \multirow{3}{*}{ Traditional } & Traditional Hospital & 32 & 3.18 & 16 & 2.17 & 46,740 & 12.50 \\
\hline & & Traditional Clinic & 5 & 0.50 & 2 & 0.20 & 32,100 & 9.80 \\
\hline & & Total & 37 & 3.67 & 18 & 2.37 & 44,761 & 12.14 \\
\hline & Total & & 1,007 & 100.00 & 752 & 100.00 & 79,624 & 10.55 \\
\hline \multirow{10}{*}{2013} & \multirow{6}{*}{ Western } & Tertiary Hospital & 8 & 0.68 & 13 & 1.41 & 206,721 & 7.75 \\
\hline & & General Hospital & 186 & 15.74 & 192 & 21.49 & 117,806 & 9.83 \\
\hline & & Hospital & 465 & 39.34 & 390 & 43.78 & 104,115 & 8.94 \\
\hline & & Long-term care hospital & 61 & 5.16 & 14 & 1.57 & 93,890 & 3.52 \\
\hline & & Western Clinic & 398 & 33.67 & 262 & 29.42 & 64,569 & 11.39 \\
\hline & & Total & 1,118 & 94.59 & 871 & 97.67 & 92,491 & 9.65 \\
\hline & \multirow{3}{*}{ Traditional } & Traditional Hospital & 60 & 5.08 & 20 & 2.23 & 66,044 & 6.93 \\
\hline & & Traditional Clinic & 4 & 0.34 & 1 & 0.11 & 22,968 & 11.50 \\
\hline & & Total & 64 & 5.41 & 21 & 2.33 & 63,352 & 7.22 \\
\hline & Total & & 1,182 & 100.00 & 891 & 100.00 & 90,913 & 9.52 \\
\hline \multirow{10}{*}{2014} & \multirow{6}{*}{ Western } & Tertiary Hospital & 9 & 0.66 & 10 & 0.92 & 200,250 & 6.00 \\
\hline & & General Hospital & 214 & 15.65 & 234 & 22.08 & 127,396 & 10.31 \\
\hline & & Hospital & 625 & 45.72 & 533 & 50.31 & 105,591 & 8.72 \\
\hline & & Long-term care hospital & 72 & 5.27 & 24 & 2.27 & 92,879 & 5.67 \\
\hline & & Western Clinic & 376 & 27.51 & 235 & 22.22 & 63,569 & 10.69 \\
\hline & & Total & 1,296 & 94.81 & 1,036 & 97.81 & 96,951 & 9.36 \\
\hline & \multirow{3}{*}{ Traditional } & Traditional Hospital & 61 & 4.46 & 20 & 1.90 & 58,725 & 7.28 \\
\hline & & Traditional Clinic & 10 & 0.73 & 3 & 0.29 & 25,945 & 12.80 \\
\hline & & Total & 71 & 5.19 & 23 & 2.19 & 54,108 & 8.06 \\
\hline & Total & & 1,367 & 100.00 & 1,059 & 100.00 & 94,726 & 9.30 \\
\hline
\end{tabular}

* Patients with overlapping records were tallied as one patient (overlap not allowed). ${ }^{\dagger}$ Costs determined to be eligible for reimbursement by the HIRA (Health Insurance Review and Assessment Service) out of the total treatment amount were indicated in the submitted insurance claim statement. They are expressed as means and are in Korean Won $(1,000,000 \mathrm{KRW}) .{ }^{\ddagger}$ Per diem is the average daily cost of services covered by National Health Insurance. ${ }^{\S}$ Days per episode are the total number of hospitalized days divided by the total number of hospitalizations. 
TABLE 17: Number of outpatient visits for ankle and foot level lesions [S93] by hospital type.

\begin{tabular}{|c|c|c|c|c|c|c|c|c|}
\hline \multirow{2}{*}{ Year } & \multirow{2}{*}{$\begin{array}{l}\text { Type of } \\
\text { medicine }\end{array}$} & \multirow[b]{2}{*}{ Hospital type } & \multicolumn{2}{|c|}{ Frequency } & \multicolumn{3}{|c|}{ Outpatient costs } & \multirow{2}{*}{$\begin{array}{c}\text { LOS } \\
\text { Days per } \\
\text { episode }\end{array}$} \\
\hline & & & $N^{*}$ & $\%$ & $\operatorname{Cost}^{\dagger}$ & $\%$ & Per diem ${ }^{\ddagger}$ & \\
\hline \multirow{14}{*}{2011} & \multirow{10}{*}{ Western } & Tertiary Hospital & 559 & 0.23 & 46 & 0.79 & 71,456 & 1.84 \\
\hline & & General Hospital & 4,204 & 1.69 & 285 & 4.88 & 54,910 & 1.60 \\
\hline & & Hospital & 10,466 & 4.22 & 571 & 9.77 & 35,586 & 1.69 \\
\hline & & Long-term care hospital & 465 & 0.19 & 18 & 0.31 & 23,088 & 1.90 \\
\hline & & Clinic & 107,340 & 43.28 & 2,471 & 42.30 & 23,025 & 1.00 \\
\hline & & Dental Hospital & 6 & 0.00 & 0 & 0.01 & 16,350 & 2.67 \\
\hline & & Public Health Center & 10 & 0.00 & 0 & 0.00 & 3,012 & 1.00 \\
\hline & & Local Public Health Clinic & 18 & 0.01 & 0 & 0.00 & 7,036 & 2.56 \\
\hline & & Public Health Hospital & 79 & 0.03 & 2 & 0.04 & 31,605 & 1.52 \\
\hline & & Total & 123,147 & 49.65 & 3,395 & 58.10 & 25,402 & 1.09 \\
\hline & \multirow{3}{*}{ Traditional } & Traditional Hospital & 1,141 & 0.46 & 45 & 0.78 & 18,915 & 2.03 \\
\hline & & Traditional Clinic & 123,750 & 49.89 & 2,403 & 41.12 & 19,416 & 1.03 \\
\hline & & Total & 124,891 & 50.35 & 2,448 & 41.90 & 19,412 & 1.04 \\
\hline & Total & & 248,038 & 100.00 & 5,843 & 100.00 & 22,386 & 1.06 \\
\hline \multirow{14}{*}{2012} & \multirow{10}{*}{ Western } & Tertiary Hospital & 769 & 0.30 & 50 & 0.80 & 64,899 & 1.51 \\
\hline & & General Hospital & 5,806 & 2.23 & 310 & 5.00 & 53,426 & 1.27 \\
\hline & & Hospital & 17,632 & 6.76 & 625 & 10.07 & 35,457 & 1.06 \\
\hline & & Long-term care hospital & 903 & 0.35 & 19 & 0.31 & 21,587 & 1.12 \\
\hline & & Clinic & 107,284 & 41.16 & 2,589 & 41.71 & 24,132 & 1.00 \\
\hline & & Dental Hospital & 31 & 0.01 & 1 & 0.01 & 26,883 & 1.00 \\
\hline & & Public Health Center & 14 & 0.01 & 0 & 0.00 & 4,871 & 1.00 \\
\hline & & Local Public Health Clinic & 23 & 0.01 & 0 & 0.00 & 9,318 & 4.30 \\
\hline & & Public Health Hospital & 82 & 0.03 & 3 & 0.04 & 31,415 & 1.39 \\
\hline & & Total & 132,544 & 50.85 & 3,597 & 57.96 & 27,142 & 1.03 \\
\hline & \multirow{3}{*}{ Traditional } & Traditional Hospital & 2,414 & 0.93 & 54 & 0.86 & 22,190 & 1.06 \\
\hline & & Traditional Clinic & 125,678 & 48.22 & 2,556 & 41.18 & 20,336 & 1.03 \\
\hline & & Total & 128,092 & 49.15 & 2,609 & 42.04 & 20,371 & 1.03 \\
\hline & Total & & 260,636 & 100.00 & 6,207 & 100.00 & 23,814 & 1.03 \\
\hline \multirow{14}{*}{2013} & \multirow{10}{*}{ Western } & Tertiary Hospital & 752 & 0.28 & 50 & 0.76 & 66,703 & 1.68 \\
\hline & & General Hospital & 6,417 & 2.39 & 357 & 5.40 & 55,586 & 1.22 \\
\hline & & Hospital & 18,960 & 7.05 & 675 & 10.22 & 35,603 & 1.05 \\
\hline & & Long-term care hospital & 773 & 0.29 & 17 & 0.25 & 21,454 & 1.10 \\
\hline & & Clinic & 109,956 & 40.91 & 2,731 & 41.35 & 24,835 & 1.00 \\
\hline & & Dental Hospital & 4 & 0.00 & 0 & 0.00 & 25,545 & 1.00 \\
\hline & & Public Health Center & 28 & 0.01 & 0 & 0.00 & 2,908 & 1.00 \\
\hline & & Local Public Health Clinic & 23 & 0.01 & 0 & 0.00 & 6,697 & 2.83 \\
\hline & & Public Health Hospital & 70 & 0.03 & 2 & 0.03 & 30,855 & 1.23 \\
\hline & & Total & 136,983 & 50.96 & 3,832 & 58.02 & 27,972 & 1.02 \\
\hline & \multirow{3}{*}{ Traditional } & Traditional Hospital & 2,255 & 0.84 & 52 & 0.79 & 23,228 & 1.05 \\
\hline & & Traditional Clinic & 129,546 & 48.20 & 2,720 & 41.18 & 20,994 & 1.02 \\
\hline & & Total & 131,801 & 49.04 & 2,772 & 41.98 & 21,032 & 1.02 \\
\hline & Total & & 268,784 & 100.00 & 6,604 & 100.00 & 24,569 & 1.02 \\
\hline \multirow{14}{*}{2014} & & Tertiary Hospital & 634 & 0.23 & 53 & 0.76 & 83,468 & 1.66 \\
\hline & & General Hospital & 7,410 & 2.72 & 415 & 5.95 & 56,052 & 1.27 \\
\hline & & Hospital & 19,690 & 7.24 & 715 & 10.25 & 36,321 & 1.05 \\
\hline & & Long-term care hospital & 747 & 0.27 & 17 & 0.25 & 23,249 & 1.08 \\
\hline & & Clinic & 111,528 & 41.01 & 2,884 & 41.34 & 25,857 & 1.00 \\
\hline & Western & Dental Hospital & 3 & 0.00 & 0 & 0.00 & 19,330 & 1.00 \\
\hline & & Public Health Center & 12 & 0.00 & 0 & 0.00 & 4,125 & 1.00 \\
\hline & & Local Public Health Clinic & 16 & 0.01 & 0 & 0.00 & 10,259 & 4.63 \\
\hline & & Public Health Hospital & 67 & 0.02 & 2 & 0.03 & 28,492 & 1.03 \\
\hline & & Total & 140,107 & 51.52 & 4,087 & 58.58 & 29,169 & 1.03 \\
\hline & & Traditional Hospital & 2,080 & 0.76 & 51 & 0.73 & 24,517 & 1.04 \\
\hline & Traditional & Traditional Clinic & 129,744 & 47.71 & 2,839 & 40.69 & 21,880 & 1.02 \\
\hline & & Total & 131,824 & 48.48 & 2,890 & 41.42 & 21,922 & 1.02 \\
\hline & Total & & 271,931 & 100.00 & 6,977 & 100.00 & 25,656 & 1.03 \\
\hline
\end{tabular}

\footnotetext{
${ }^{*}$ Patients with overlapping records were tallied as one patient (overlap not allowed). ${ }^{\dagger}$ Costs determined to be eligible for reimbursement by the HIRA (Health Insurance Review and Assessment Service) out of the total treatment amount were indicated in the submitted insurance claim statement. They are expressed as means and are in Korean Won $(1,000,000 \mathrm{KRW}) .{ }^{\ddagger}$ Per diem is the average daily cost of services covered by National Health Insurance. ${ }^{\S}$ Days per episode are the total number of outpatient visit days including drug prescription days divided by the total number of outpatient visits.
} 
TABLE 18: Distribution of nonsurgical interventions in Western medicine and traditional Korean medicine.

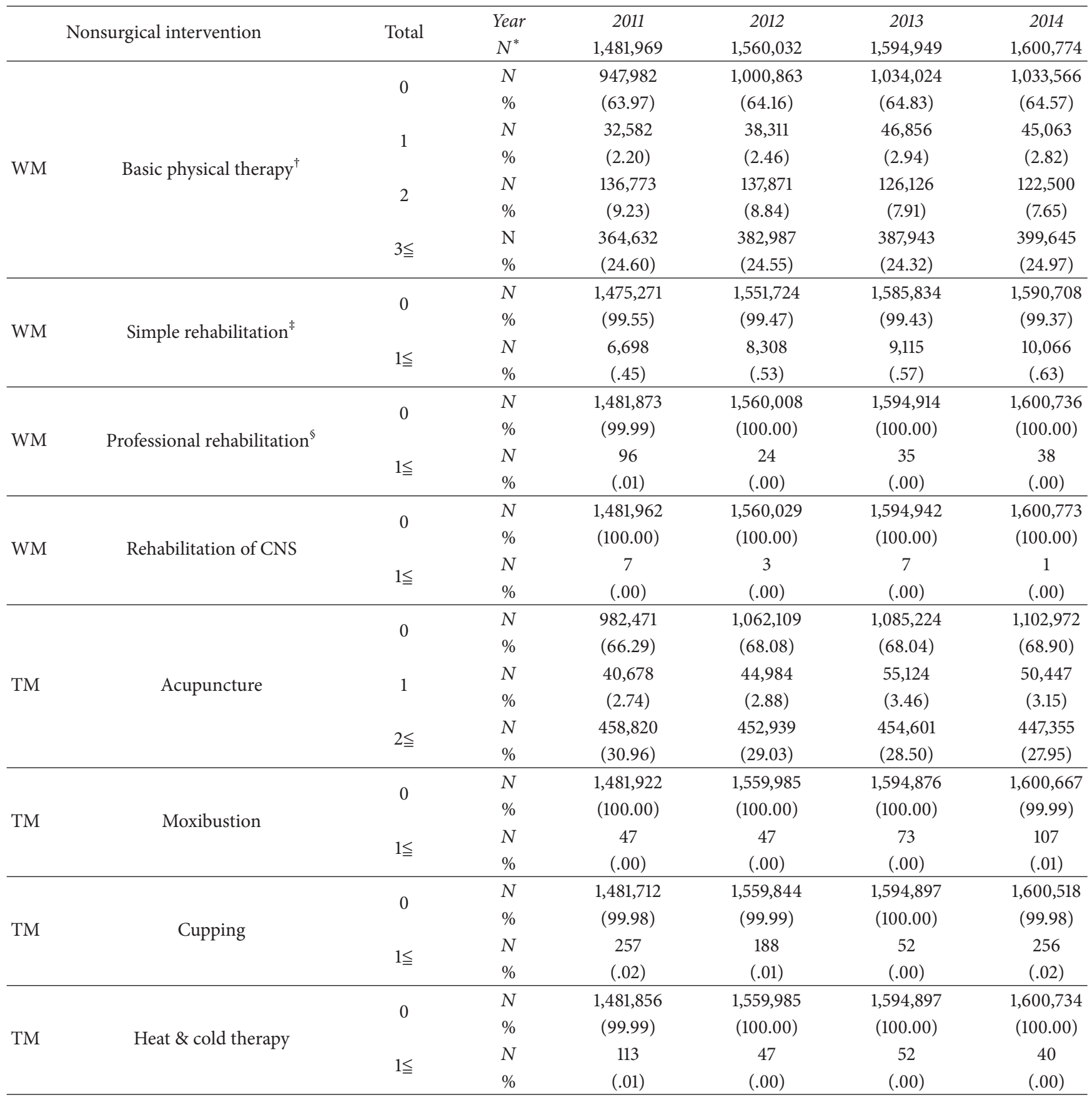

${ }^{*}$ A patient could be hospitalized more than once during the study period, resulting in more than one claim per patient. Thus, the number of claims in the study was higher than the number of patients. ${ }^{\dagger}$ Basic physical therapy included superficial heat therapy, cold therapy, deep heat therapy, ultraviolet irradiation, transcutaneous electrical nerve stimulation, massage therapy, and simple therapeutic exercise. ${ }^{\ddagger}$ Simple rehabilitation included paraffin bath, hydrotherapy, intermittent traction therapy, electrical stimulation therapy, laser therapy, therapeutic exercise, motor point block, pneumatic compression, complex decongestive physical therapy, and iontophoresis. ${ }^{\S}$ Professional rehabilitation included pool therapy, occupational therapy, activities of daily living training, neurogenic bladder training, functional electrical stimulation therapy, myofascial trigger point injection, rehabilitative social work, rehabilitative breathing therapy, rehabilitative functional training, and rehabilitative dysphagia therapy. WM, Western medicine; TM, traditional Korean medicine.

Despite the high demand for traditional Korean medicine for musculoskeletal diseases, traditional Korean medical practitioners are precluded from diagnosing joint disorders independently due to regulatory restrictions in imaging device use. We confirmed this fact again by comparing subgroup costs related to the type of medicine in total treatment cost. Apart from procedures such as acupuncture, moxibustion, and cupping, many treatments were not covered by the NHI (Table 7). Large variations in diagnostic and therapeutic management between Western medicine 
and traditional Korean medicine indicate that more items in Korean medicine need to be covered and developed. Among the hospitalized patients, the number of claims for all years after 2011 increased mostly for shoulder joints $(78.43 \%)$ compared to 2011 , followed by knees $(61.93 \%)$, foot $(50.72 \%)$, and hands $(16.29 \%)$. While the rate of use of traditional Korean medicine for the shoulder region slightly decreased in outpatient care, the number of hospitalizations increased sharply (Table 9). It is interesting that the proportion of traditional hospitalization increase for the knee and shoulder regions (shoulder: $105.00 \%$, knee: $250.00 \%$ ) was higher than that of Western medicine clinic hospitalization (shoulder: 77.99\%, knee: 58.04\%). In Korea, the medical delivery system of traditional medicine is not strict. Individuals can choose to visit primary medical institutions (Traditional Clinic) and higher medical institutions (Traditional Hospital). Shoulder and knee joint diseases are common musculoskeletal diseases. They are usually treated in primary care settings. However, if there is no response or a lack of effectiveness in primary care, a Traditional Hospital is attended for a more accurate diagnosis and evaluation. This might be the reason why there is increase in hospitalization in Traditional Hospitals that hire orthodox medical practitioners who can use Xrays and magnetic resonance imaging. Besides, because traditional medical practitioners cannot use these examination devices in a Traditional Clinic, outpatient care in Traditional Clinics was much lower compared to that in Western Clinics. Although simple radiology is helpful in the diagnosis of joint disease [28], patient might suffer the inconvenience of going to both Western and Traditional Clinics for accurate diagnosis due to legal restrictions [29].

Traditional Korean medicine had lower medical expenditures than Western medicine (inpatient care cost: Western medicine clinic, 160,000 KRW; traditional Korean medicine clinic, 50,000 KRW; outpatient care cost: Western medicine, 22,000 KRW; traditional Korean medicine, 18,000 KRW). The average treatment cost for traditional Korean medicine was lower compared to that for Western medicine. RPE ranged from 181,225 KRW to 198,661 KRW for Western medicine and 82,019 KRW to 96,325 KRW for traditional Korean medicine. In addition, out-of-pocket expenses for Western medicine $(44,240 \mathrm{KRW}$ to $49,621 \mathrm{KRW})$ were higher than those of traditional Korean medicine (20,154 KRW to $22966 \mathrm{KRW})$. Although expenditures for traditional Korean medicine were significantly lower compared to those for Western medicine, daily cost amount showed no significant difference between the two depending on the year. These results are similar to those of a previous study [6].

Most patients had mild joint diseases (more than 70\%) with CCI scores of 0 and underwent nonsurgical treatment. Regardless of disease type, the proportion of surgery was less than $1 \%$. Therefore, traditional medical care can serve as an alternative to Western medical care. We found that the proportion of acupuncture was slightly higher than basic physical therapy (Table 18). However, further research is needed to confirm that traditional Korean medicine is costeffective for managing joint diseases.

This study has several limitations. First, the study was descriptive in nature. It reported sociodemographic characteristics, procedures, medication, and average cost for treating joint disorders without addressing a specific hypothesis.
Recently, research results have been utilized as basis for policies by utilizing health-related big data. However, there is a lack of data analyzing various patterns of traditional medical services [30]. Although there are studies that use NHI claims data, they are limited to a single year or disease range $[8,13]$. This study is novel in that it compared the utilization of Western medicine and traditional Korean medicine for the treatment of joint disorders in Korea. We believe the current study would serve as a good reference for countries with similar medical systems as that of Korea and would be able to contribute to international literature. Further research is required, such as analysis of factors influencing the use or frequency of Korean traditional medicine using multivariate statistics.

Second, while fee-for-service for nationally covered health care service was comprehensively recorded in the claim database, nonreimbursable items such as traditional drugs did not generate billing data. In addition, we only calculated direct medical costs based on information in the claim database. In general, there are nonmedical costs such as transportation costs and lost productivity due to morbidity because joint diseases tend to be chronic. In addition, the costs did not uncover items based on claims data that only contained information about medical services provided under the NHI. If uncovered items were included, the costs for traditional Korean medicine might be higher than that of Western medicine. In a previous study [31] comparing Western and traditional Korean medicine users, it was found that the traditional Korean medicine user group paid significantly more medical expenses than the Western medicine user group. In a study on the determinants of traditional Korean medicine use based on panel data [32], the number of patients using traditional Korean medicine was significantly higher than those using Western medicine. This is because the insurance benefit for traditional Korean medicine is lower than that for Western medicine.

Third, we did not include essential factors influencing choice of medical practice, such as education level, income, residence, severity, and health-related risk factors (e.g., alcohol consumption, smoking, and exercise) [33]. Previous studies have shown that factors affecting the use of traditional Korean medicine are not related to education level or income level [34, 35], high education level [14], low education level $[36,37]$, and low or high-income level [32]. In previous studies, factors such as the use of a therapist [33], confidence in oriental medical institution [32], recognition of therapeutic effect [38], and coping attitude of the oriental medical treatment [39] have been found to be significant factors. Although these essential variables are important parameters in choosing hospitals, they were missed due to the nature of the claims data. To overcome the omission of disturbance variables, medical insurance type (NHI or Medicaid) and region of hospital were used as surrogates of income and residence in this study. In addition, we considered disease severity by using CCI because severity of disease might greatly affect hospital choice. The remaining factors have been judged due to their impacts on health care utilization. We believe that the direction of the analysis of this study will not change. Due to the limitation in data characteristics, these elements were 
not included in this study. Future studies considering these factors are needed to confirm our findings.

Finally, the accuracy of diagnoses has been an issue due to the nature of claims data collected with the purpose of reimbursing health care services and not for clinical purposes [18]. The accuracy of diagnosis in the KNHI claims data has been reported to be about 70\% [40]. Moreover, the accuracy of disease classification has been reported to be higher for inpatients than for outpatients. It is higher for severe disorders than for common mild disorders. It is also higher in General Hospitals than in clinics [41]. Nonetheless, in the process of designing this study, physicians in current practice concurred that these codes were not clearly differentiated for diagnosis in actual clinical practice settings in Korea. Therefore, analysis was performed in primary and secondary diagnoses in accordance with the opinion that various issues should be taken into account (e.g., private insurance, medical care institution characteristics, and individual differences in physicians) in category division. In addition, primary and secondary diagnoses are generally used in conjunction [14]. Therefore, in defining medical care usage due to joint disease, we reviewed not only the major diagnosis code, but also secondary diagnosis code. Despite our efforts, the diagnosis accuracy for joint diseases in this study might be challenged.

Despite these limitations, our study has several strengths. First, we analyzed age-stratified and gender-stratified random samples of the KNHI claims database representing 98\% of the South Korean population. Claims statements covered extensive information on health care interventions (e.g., treatment, procedures, diagnostic tests, and prescription drugs), diagnosis, NHI payment cost, beneficiaries' out-of-pocket expenses, sociodemographic characteristics, and medical institutions, thus providing useful nationwide epidemiological data. Its representativeness, reliability, and validity have been confirmed previously [41]. However, there is a lack of data necessary to understand various consumption patterns and supply patterns of traditional medical services [30].

Second, there are studies in other countries that analyze the status of traditional Korean medicine utilization by using representative data source [30, 42-44]. Unlike most previous clinical studies whose duration was less than one year, we attempted to analyze the change over four years for joint diseases based on the type of medicine used (Western or traditional Korean medicine). Until now, no studies have reported national data on the management of joint disorders for 2011 to 2014. This study holds significance in that it is the first study that reports distinct differences in patterns of medical care use and costs between Western medicine and traditional Korean medicine.

An added strength of this study was that it provided patterns of complementary and alternative medicine treatment for joint disorders in Korea by covering traditional Korean medicine treatments as acupuncture, moxibustion, and cupping in the NHI.

Third, we constructed pilot medical episode data considering characteristics of health claim data for joint diseases. This can be used as a data processing technique to calculate basic dynamics information. Health insurance claim data were produced by physicians based on diagnosis at the first visit to the hospital. Related claim data were then produced, including the diagnosis code, the date of initiation of treatment (hospitalization or outpatient), and personal information (age, sex). To use epidemiological data, it is necessary to link the billing statement classified for administrative purposes to the same hospitalization case [45]. In this study, the same patient filed a billing statement with the same hospital in the same medical institution for inpatient care. The date was connected to one hospitalization case.

Our study has several policy implications. As disease structure can change from acute to chronic degenerative disease, interest in traditional medicine is increasing with aging. The main purpose of traditional medicine use in South Korea is to prevent disease and promote general health [10]. Though traditional medicine plays a substantial role in the Korean health care system, the annual number of health insurance claims from traditional Korean medicine institutions has stagnated and decreased since 2012 [46]. Medical use is affected by demographic, socioeconomic, and psychocultural factors. It has been reported that these factors can affect health care utilization by interactions between factors rather than independent factors $[47,48]$. Therefore, it is important to grasp the current position of traditional Korean medicine in order to prepare policy and directives. Currently, difference in standards of practice underlies mistrust for traditional Korean medicine among Western medical practitioners [6]. To overcome conflicts among orthodox and traditional practitioners, we need an effective health care delivery system that encourages consultation for both Western and traditional Korean medicine with accessibility. Further discussion must be considered by providing consultation programs for other chronic diseases and joint diseases.

\section{Conclusions}

This study provided objective information about epidemiologic characteristics of patients with joint disorders treated with Western medicine and traditional Korean medicine. It provided an understanding about the recent status and trends. It will provide a basis for further expansion of traditional Korean medicine for patients with muscular disorders. Based on HIRA data, medical use for joint disorders showed significant difference between the groups. It provides basic information for future usual care guidelines linked to health policy and budget appropriation. Timely and accurate information is essential for policy-makers to make decisions. The results of our study will contribute to management decisions for musculoskeletal diseases involving joint disorders.

\section{Abbreviations}

HIRA: Health Insurance Review \& Assessment Services

NHIS: National Health Insurance Sample

WM: Western medicine

TM: Traditional Korean medicine. 


\section{Additional Points}

Availability of Data and Material. Datasets generated and/or analyzed in the current study are available from the HIRANPS repository. HIRA data are third-party data not owned by the authors. HIRA data are available upon visit or by mail upon direct, email, or fax submission of dataset request form and declaration of data use downloadable from the "HIRA" website: [http://opendata.hira.or.kr/op/opc/selectPatDataAplInfoView.do] and upon payment of the transfer of data request fee $(300,000 \mathrm{KRW}$ per dataset).

\section{Ethical Approval}

The HIRA Research Ethics Committee of South Korea approved the protocol of this study.

\section{Disclosure}

Written informed consent was not obtained from participants because only clinical records were used in this study based on national billing data submitted to HIRA. Patient information was anonymized and deidentified by HIRA prior to analysis in this study.

\section{Conflicts of Interest}

The authors declare that there are no conflicts of interest regarding the publication of this article.

\section{Authors' Contributions}

Soyoon Kim constructed study design, Sukjin Bae analyzed the data, and Boyoung Jung interpreted the results. Soyoon Kim was scientific advisor and directed this study. Boyoung Jung wrote the manuscript and performed the statistical analysis. All authors read and approved the final manuscript.

\section{Acknowledgments}

This study was supported by Research Institute of Korean Medicine Policy.

\section{References}

[1] P. M. Brooks, "The burden of musculoskeletal disease-a global perspective," Clinical Rheumatology, vol. 25, no. 6, pp. 778-781, 2006.

[2] I.-H. Oh, S.-J. Yoon, H.-Y. Seo, E.-J. Kim, and Y. A. Kim, “The economic burden of musculoskeletal disease in Korea: A cross sectional study," BMC Musculoskeletal Disorders, vol. 12, article no. 157, 2011.

[3] N. Hur, C. Choi, W. Uhm, and S. Bae, "The Prevalence and Trend of Arthritis in Korea: Results from Korea National Health and Nutrition Examination Surveys," The Journal of the Korean Rheumatism Association, vol. 15, no. 1, pp. 11-26, 2008.

[4] H. Choi, W. Han, J. Im, and H. Baek, "The Prevalence and Clinical Features of Musculoskeletal Diseases in Incheon: Results from Chronic Disease Management Surveys," The Journal of the Korean Rheumatism Association, vol. 16, no. 4, pp. 281-290, 2009.

[5] S. Brage, J. F. Nygard, and G. Tellnes, "The gender gap in musculoskeletal-related long term sickness absence in Norway," Scandinavian Journal of Social Medicine, vol. 26, no. 1, pp. 34-43, 1997.

[6] A. D. Woolf and K. Åkesson, "Understanding the burden of musculoskeletal conditions," British Medical Journal, vol. 322, no. 7294, pp. 1079-1080, 2001.

[7] G. Bodeker, "Lessons on integration from the developing world's experience," British Medical Journal, vol. 322, no. 7279, pp. 164-167, 2001.

[8] Y.-J. Ahn, J.-S. Shin, J. Lee et al., "Evaluation of use and cost of medical care of common lumbar disorders in Korea: Cross-sectional study of Korean Health Insurance Review and Assessment Service National Patient Sample data," BMJ Open, vol. 6, no. 9, Article ID e012432, 2016.

[9] J. Kim and M. Son, "National Health Insurance Statistical Yearbook," Seoul: Health Insurance Review and Assessment Service and National Health Insurance Service, 2017.

[10] E. M. Badley, I. Rasooly, and G. K. Webster, "Relative importance of musculoskeletal disorders as a cause of chronic health problems, disability, and health care utilization: Findings from the 1990 Ontario Health Survey," The Journal of Rheumatology, vol. 21, no. 3, pp. 505-514, 1994.

[11] P. C. Coyte, C. V. Asche, R. Croxford, and B. Chan, “The economic cost of musculoskeletal disorders in Canada," Arthritis \& Rheumatology, vol. 11, no. 5, pp. 315-325, 1998.

[12] D. P. Lubeck, "The costs of musculoskeletal disease: Health needs assessment and health economics," Best Practice of Research Clinical Rheumatology, vol. 17, no. 3, pp. 529-539, 2003.

[13] H. Joo, Y. J. Lee, J. Shin et al., "Medical service use and usual care of common shoulder disorders in Korea: a cross-sectional study using the Health Insurance Review and Assessment Service National Patient Sample," BMJ Open, vol. 7, no. 7, Article ID e015848, 2017.

[14] J. M. Gill and A. G. Mainous III, "The Role of Provider Continuity in Preventing Hospitalizations," Archives of Family Medicine, vol. 7, no. 4, pp. 352-357, 1998.

[15] E. Yelin and L. F. Callahan, "Special article the economic cost and social and psychological impact of musculoskeletal conditions," Arthritis \& Rheumatism, vol. 38, no. 10, pp. 1351-1362, 1995.

[16] L. J. Weiss and J. Blustein, "Faithful patients: The effect of longterm physician-patient relationships on the costs and use of health care by older Americans," American Journal of Public Health, vol. 86, no. 12, pp. 1742-1747, 1996.

[17] J. McLeod, J. McMurray, J. D. Walker, G. A. Heckman, and P. Stolee, "Care transitions for older patients with musculoskeletal disorders: continuity from the providers' perspective," International Journal of Integrated Care, vol. 11, no. 2, 2011.

[18] L. Kim, J.-A. Kim, and S. Kim, "A guide for the utilization of Health Insurance Review and Assessment Service National Patient Samples," Epidemiology and Health, vol. 36, Article ID e2014008, 2014.

[19] D. T. Felson, A. Naimark, J. Anderson, L. Kazis, W. Castelli, and R. F. Meenan, "The prevalence of knee osteoarthritis in the elderly. The Framingham Osteoarthritis Study," Arthritis \& Rheumatism, vol. 30, no. 8, pp. 914-918, 1987.

[20] G. Tellnes and T. Bjerkedal, "Epidemiology of sickness certification - A methodological approach based on a study from 
Buskerud county in Norway," Scandinavian Journal of Social Medicine, vol. 17, no. 3, pp. 245-251, 1989.

[21] V. Sundararajan, T. Henderson, C. Perry, A. Muggivan, H. Quan, and W. A. Ghali, "New ICD-10 version of the Charlson comorbidity index predicted in-hospital mortality," Journal of Clinical Epidemiology, vol. 57, no. 12, pp. 1288-1294, 2004.

[22] H. Quan, V. Sundararajan, P. Halfon et al., "Coding algorithms for defining comorbidities in ICD-9-CM and ICD-10 administrative data," Medical Care, vol. 43, no. 11, pp. 1130-1139, 2005.

[23] P. Sloane and C. Egelhoff, "The relationship of continuity of care to age, sex, and race," Journal of Family Practice, vol. 16, no. 2, pp. 402-405, 1983.

[24] M. F. Fleming, E. J. Bentz, E. J. Shahady, A. Abrantes, and C. Bolick, "Effect of case mix on provider continuity," Journal of Family Practice, vol. 23, no. 2, pp. 137-140, 1986.

[25] R. C. Lawrence, C. G. Helmick, F. C. Arnett et al., "Estimates of the prevalence of arthritis and selected musculoskeletal disorders in the United States," Arthritis \& Rheumatology, vol. 41, no. 5, pp. 778-799, 1998.

[26] J. Kim and M. Son, "National Health Insurance Statistical Yearbook. Seoul: Health Insurance Review and Assessment Service and National Health Insurance Service," 2014.

[27] H.-A. Kim, S. Kim, Y. I. Seo et al., "The epidemiology of total knee replacement in South Korea: national registry data," Rheumatology, vol. 47, no. 1, pp. 88-91, 2008.

[28] J. H. Kellgren and J. S. Lawrence, "Radiological assessment of osteo-arthrosis," Annals of the Rheumatic Diseases, vol. 16, no. 4, pp. 494-501, 1957.

[29] A. D. Woolf and B. Pfleger, "Burden of major musculoskeletal conditions," Bulletin of the World Health Organization, vol. 81, no. 9, pp. 646-656, 2003.

[30] K. Han, I. Ha, and J. Lee, "Application of Health Care Big data and Necessity of Traditional Korean Medicine Data Registry," Journal of Korean Medicine for Obesity Research, vol. 17, no. 1, pp. 46-53, 2017.

[31] X. Kang, M. Fransen, Y. Zhang et al., “The high prevalence of knee osteoarthritis in a rural chinese population: the wuchuan osteoarthritis study," Arthritis Care Research, vol. 61, no. 5, pp. 641-647, 2009.

[32] I. Kim, H. A. Kim, Y.-I. Seo, Y. W. Song, J.-Y. Jeong, and D. H. Kim, "The prevalence of knee osteoarthritis in elderly community residents in Korea," Journal of Korean Medical Science, vol. 25, no. 2, pp. 293-298, 2010.

[33] M. Blagojevic, C. Jinks, A. Jeffery, and K. P. Jordan, "Risk factors for onset of osteoarthritis of the knee in older adults: a systematic review and meta-analysis," Osteoarthritis and Cartilage, vol. 18, no. 1, pp. 24-33, 2010.

[34] Y.-J. Choi, S.-H. Kang, and Y.-I. Kim, "Association of higher continuity of primary care with lower risk of hospitalization among children and adolescent patients," Korean Journal of Health Policy and Administration, vol. 18, pp. 85-107, 2008.

[35] J. M. Gill, A. G. Mainous 3rd, J. J. Diamond, and M. J. Lenhard, "Impact of provider continuity on quality of care for persons with diabetes mellitus," Annals of Family Medicine, vol. 1, no. 3, pp. 162-170, 2003.

[36] D. A. Christakis, L. Mell, T. D. Koepsell, F. J. Zimmerman, and F. A. Connell, "Association of lower continuity of care with greater risk of emergency department use and hospitalization in children," Pediatrics, vol. 107, no. 3, pp. 524-529, 2001.

[37] A. Sudo, N. Miyamoto, K. Horikawa et al., "Prevalence and risk factors for knee osteoarthritis in elderly Japanese men and women," Journal of Orthopaedic Science, vol. 13, no. 5, pp. 413418, 2008.

[38] Y. Zhang, L. Xu, M. C. Nevitt et al., "“'Comparison of the prevalence of knee osteoarthritis between the elderly Chinese population in Beijing and whites in the United States: The Beijing Osteoarthritis Study," Arthritis \& Rheumatology, vol. 44, no. 9, pp. 2065-2071, 2001.

[39] H. Du, S.-L. Chen, C.-D. Bao et al., "Prevalence and risk factors of knee osteoarthritis in Huang-Pu District, Shanghai, China," Rheumatology International, vol. 25, no. 8, pp. 585-590, 2005.

[40] J. Kim, "Basis of using health insurance data, strategic, and assignment from the computation of health statistic," 2005.

[41] A. D. Woolf, “The bone and joint decade 2000-2010," Annals of the Rheumatic Diseases, vol. 59, no. 2, pp. 81-82, 2000.

[42] M. Cross, E. Smith, D. Hoy et al., "The global burden of hip and knee osteoarthritis: estimates from the global burden of disease 2010 study," Annals of the Rheumatic Diseases, vol. 73, no. 7, pp. 1323-1330, 2014.

[43] J. S. Hong, H. C. Kang, and J. Kim, "Continuity of care for elderly patients with diabetes mellitus, hypertension, asthma, and chronic obstructive pulmonary disease in Korea," Journal of Korean Medical Science, vol. 25, no. 9, pp. 1259-1271, 2010.

[44] M. C. Sokol, K. A. McGuigan, R. R. Verbrugge, and R. S. Epstein, "Impact of medication adherence on hospitalization risk and healthcare cost," Medical Care, vol. 43, no. 6, pp. 521-530, 2005.

[45] G. Peat, R. McCarney, and P. Croft, "Knee pain and osteoarthritis in older adults: a review of community burden and current use of primary health care," Annals of the Rheumatic Diseases, vol. 60, no. 2, pp. 91-97, 2001.

[46] Y. J. Song, “The south korean health care system," Japan Medical Association Journal, vol. 52, no. 3, pp. 206-209, 2009.

[47] C.-H. Yoon, S.-J. Lee, S. Choo, O.-R. Moon, and J.-H. Park, "Continuity of care of patient with diabetes and its affecting factors in Korea," Journal of Preventive Medicine \& Public Health, vol. 40, no. 1, pp. 51-58, 2007.

[48] J. Hong, J. Kim, and H. Kang, "Continuity of Ambulatory Care among Adult Patients with Type 2 Diabetes and Its Associated Factors in Korea," Korean Journal of Health Policy and Administration, vol. 19, no. 2, pp. 51-70, 2009. 


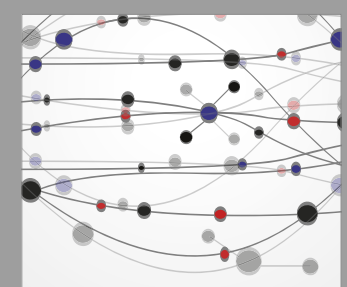

The Scientific World Journal
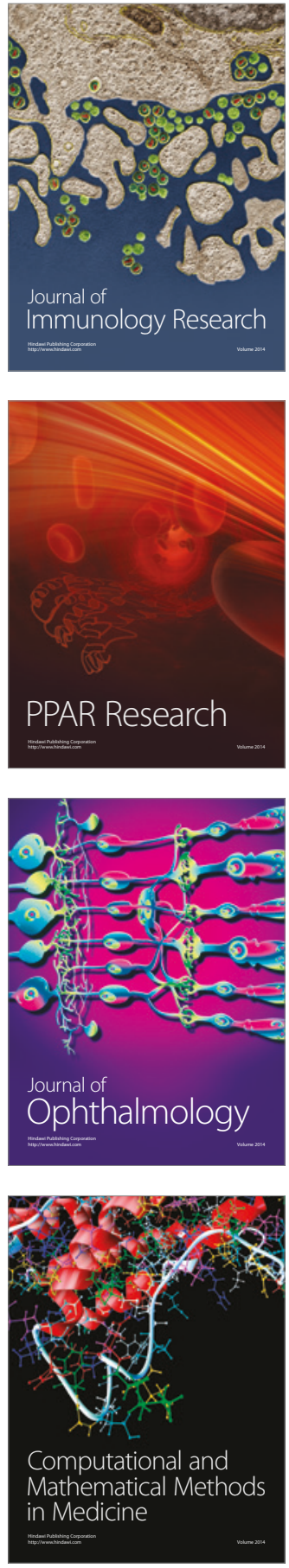

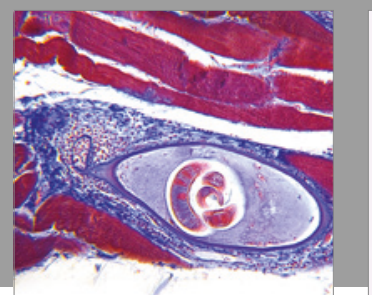

Gastroenterology Research and Practice
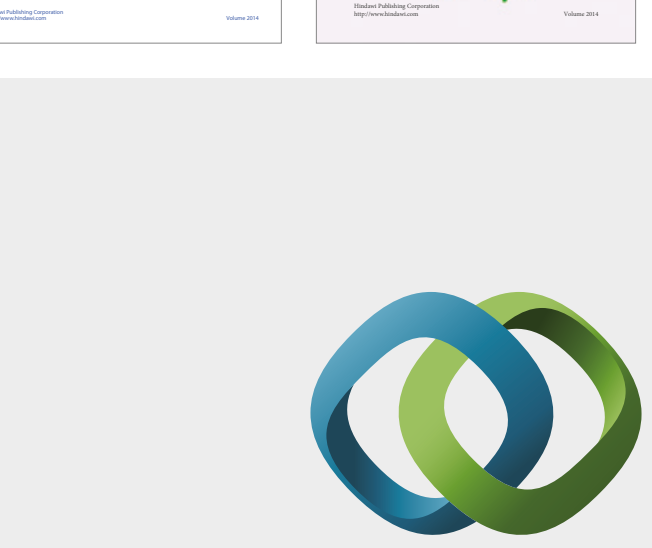

\section{Hindawi}

Submit your manuscripts at

https://www.hindawi.com
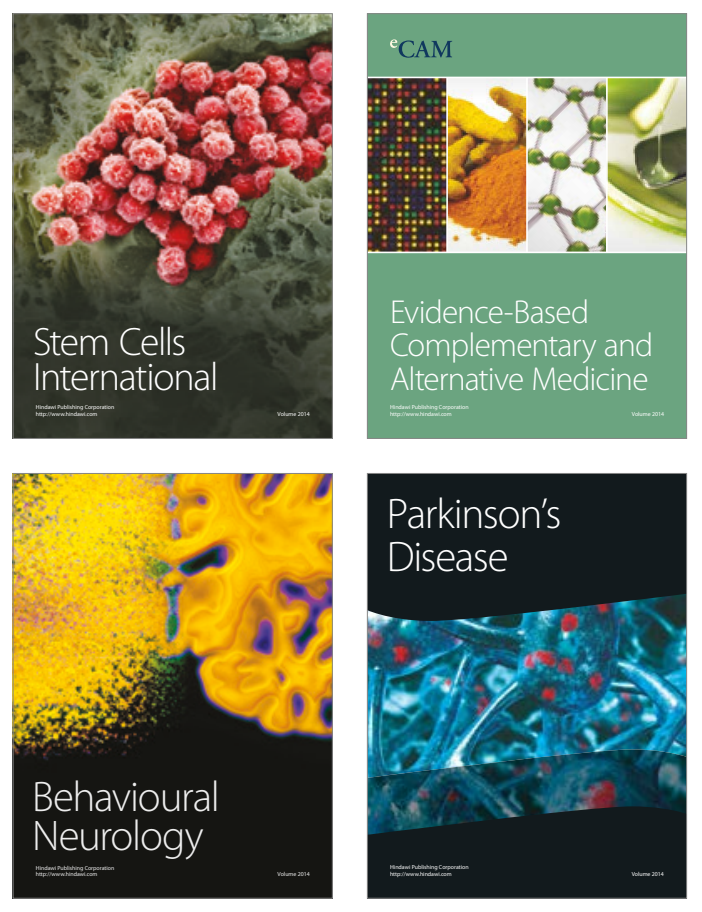
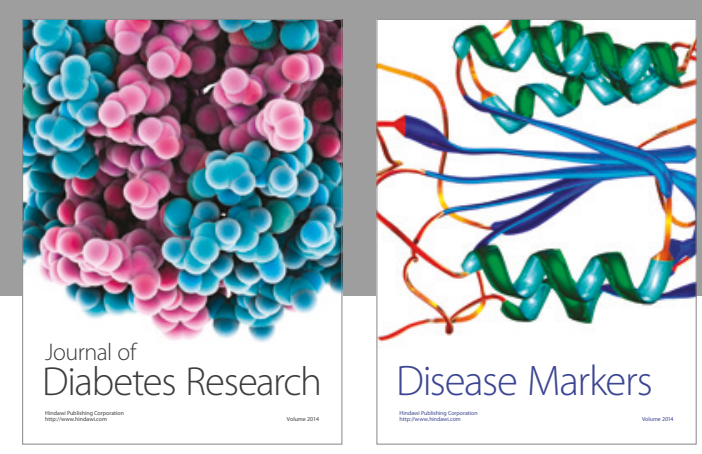

Disease Markers
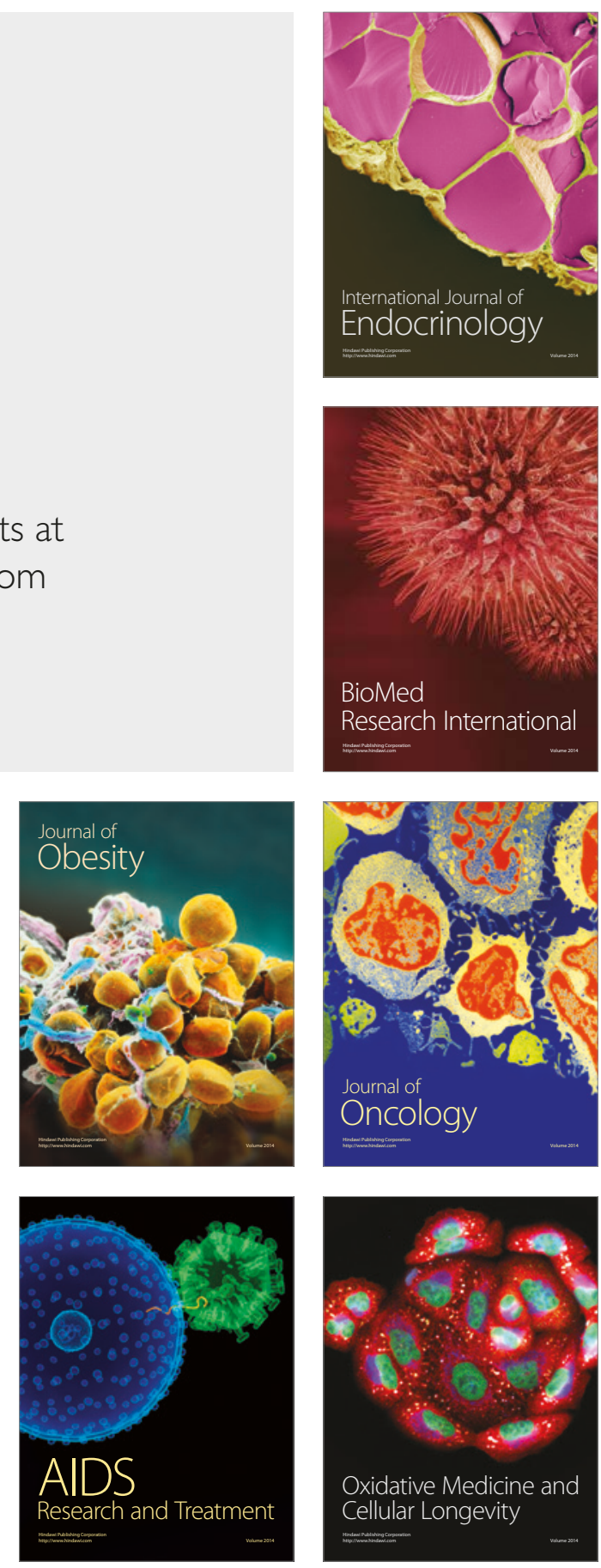